\title{
Experimental and finite element analysis of EDM process and investigation of material removal rate by response surface methodology
}

\author{
Mehrdad Hosseini Kalajahi • Samrand Rash Ahmadi • \\ Samad Nadimi Bavil Oliaei
}

Received: 23 January 2013 / Accepted: 6 May 2013 / Published online: 24 May 2013

(C) Springer-Verlag London 2013

\begin{abstract}
In this study, thermal modeling and finite element simulation of electrical discharge machining (EDM) has been done, taking into account several important aspects such as temperature-dependent material properties, shape and size of the heated zone (Gaussian heat distribution), energy distribution factor, plasma flushing efficiency, and phase change to predict thermal behavior and material removal mechanism in EDM process. Temperature distribution on the cathode has been calculated using ANSYS finite element code, and the effect of EDM parameters on heat distribution along the radius and depth of the workpiece has been obtained. Temperature profiles have been used to calculate theoretical material removal rate (MRR) from the cathode. Theoretically calculated MRRs are compared with the experimental results, making it possible to precisely determine the portion of energy that enters the cathode for AISI H13 tool steel. Also in this paper, the effect of EDM parameters on MRR has been investigated by using the technique of design of experiments and response surface methodology. Finally, a quadratic polynomial regression model has been proposed for MRR, and the accuracy of this model has been checked by means of analysis of residuals.
\end{abstract}

M. Hosseini Kalajahi · S. Rash Ahmadi

Department of Mechanical Engineering, Faculty of Engineering,

Urmia University, Urmia, Iran

M. Hosseini Kalajahi

e-mail:mehrdad_hk@yahoo.com

S. Rash Ahmadi

e-mail: s.rashahmadi@urmia.ac.ir

S. Nadimi Bavil Oliaei $(\bowtie)$

Department of Mechanical Engineering, Faculty of Engineering,

Bilkent University, Bilkent,

Ankara 06800, Turkey

e-mail: samad.nadimi@bilkent.edu.tr
Keywords EDM $\cdot$ FEM $\cdot$ MRR $\cdot$ DOE $\cdot$ RSM

$\begin{array}{ll}\text { Abbreviations } \\ \text { EDM } & \text { Electrical discharge machining } \\ \text { FEM } & \text { Finite element method } \\ \text { PFE } & \text { Plasma flushing efficiency } \\ \text { MRR } & \text { Material removal rate } \\ \text { DOE } & \text { Design of experiments } \\ \text { RSM } & \text { Response surface methodology } \\ \text { TWR } & \text { Tool wear ratio } \\ F_{\mathrm{c}} & \text { Energy distribution factor } \\ \text { PDF } & \text { Probability density function } \\ \text { ANOVA } & \text { Analysis of variance }\end{array}$

\section{Introduction}

Electrical discharge machining (EDM) is a widespread technique used in industry for high-precision machining of all types of conductive materials, such as metals, metallic alloys, graphite, and even some ceramic materials, of any hardness. Its ability to control the process parameters to achieve the required dimensional accuracy and surface finish has placed EDM in an outstanding position in industrial applications [1]. In spite of the increasing popularity of this technique, it needs to combine high material removal rate (MRR), low tool wear rate (TWR), and excellent surface quality to be more efficient in the industry. A number of researchers have shown that EDM process can be simulated through thermal models that can be used to predict the amount of material removed during a single pulse. Snoeys and Van Dijck [2] developed an electro-thermal model utilizing a semi-infinite cylinder with a disk-shaped heat input. Energy distribution factor for the cathode was assumed as 
$50 \%$. The work was followed by Van Dijck and Dutre [3] using a two-dimensional heat flow model where the medium is bounded by an adiabatic cylindrical surface in the radial direction. The work was carried out for both finite and infinite continuum. Beck $[4,5]$ was the subsequent researcher who investigated the heat distribution on the cathode using constant thermal properties and constant heat flux and neglecting the convective heat transfer. In their study, the fraction of energy transferred into the cathode was not taken into account. Jilani and Pandey $[6,7]$ presented a similar approach. They proposed a semi-infinite model considering a disk-shaped heat flux, a constant spark radius, and an energy distribution factor $\left(F_{\mathrm{c}}\right)$ of $50 \%$. The most accurate and reliable model which was presented until then was the model proposed by Dibitonto et al. [8]. This study was thus considered as a benchmark in EDM process modeling and was followed by numerous researchers. In this study, the plasma radius at the cathode was assumed to be much smaller than that at the anode. Therefore, the heat source was approximated by a point instead of disk-shaped. The energy distributed to the cathode for erosion was assumed to be $18 \%$. Panda and Bhoi [9] developed a three-dimensional transient heat conduction model of EDM process considering the growth of the plasma channel. The model, however, has limited applicability as it considered constant spark radius for all discharge conditions. It should be mentioned that none of the aforementioned studies have incorporated the effect of plasma flushing efficiency (PFE) and phase change in their models.

In an attempt to simulate the EDM process by finite element modeling, Yadav et al. [10] developed a finite element model to estimate the temperature field and thermal stresses by applying a thermal load as a Gaussian heat flux. In their study, a heat distribution factor of 0.42 has been used to calculate temperature distribution. Their model has limited applicability since they have neglected the effect of phase change, PFE, and temperature-dependent material properties, and they assumed a constant spark radius. In addition, they did not calculate the value of $F_{\mathrm{c}}$ for the material used in their study and applied the value presented by Shanker et al. [11] which has been calculated using water as the dielectric fluid and at different processing conditions. Das et al. [12] presented a finite element model which used process parameters such as power input and pulse duration to predict the transient temperature distribution and residual stresses that are induced in the workpiece as a result of a single-pulse discharge. The PFE values incorporated in their research have presented for iron not the L6 tool steel which was the material of choice for their study. In their study, they adopted a value of $18 \%$ for $F_{c}$, which is only valid for EDM of iron and cannot be generalized to the EDM of other materials. Process simulation and residual stress analysis for micro-EDM machining on molybdenum in reverse polarity is presented by Allen et al. [13]. Although they made use of Gaussian heat flux and time-dependent equation for plasma radius and they incorporated the effect of solid-to-liquid phase changes, using constant material properties and neglecting the effect of PFE can be considered as restrictions to their model. It should be mentioned that the value of $8 \%$ which has been used in this study as a portion of energy that enters into the anode is reported for iron, not for molybdenum. An axisymmetric two-dimensional model for powder-mixed electric discharge machining using the finite element method was reported by Kansal et al. [14]. The model utilizes several important aspects such as temperaturedependent material properties, shape and size of heat source (Gaussian heat distribution), phase change (enthalpy), etc., however assuming a constant value for PFE for all machining conditions $(20 \%)$ and presuming a value of $9 \%$ as a portion of energy transferred to the anode without presenting any experimental or theoretical calculation are some limitations of this study. In 2008, Yeo et al. [15] critically compared various reported EDM thermal models in terms of temperature distribution, crater geometry, and material removal at the cathode. Comparative analyses on the MRR ratio of the predicted result to experimental data for discharge energy range from 0.33 to $952 \mathrm{~mJ}$ showed that DiBitonto's model yielded the closest proximity of 1.2-46.1 MRR ratio. In 2010, Joshi et al. [16] presented an investigation on MRR simulation and shape of the crater cavity considering more realistic assumptions. They carried out their research in two phases: in the first section, they compared their results with one reported by Dibitonto et al. and reported that their model predicts results closer to experimental data; in the second phase, they investigated MRR and crater shape on AISI P20, considering the PFE as $100 \%$ and $F_{\mathrm{c}}$ as $18 \%$. Although most of the simplifying assumptions were eliminated in this study but neglecting the effect of PFE, convective heat transfer and requirement for the calculation of a more precise value of $F_{\mathrm{c}}$ will place some minor limitations on their model. Shabgard et al. [17] simulated the EDM process of AISI H13 tool steel and investigated the depth of recast and hardened layers. The lack of considering phase transformation and computing of a true value of $F_{\mathrm{c}}$ can be named as restrictions of their study.

Most of the reported theoretical models based on thermal analysis have limited applicability as they are based on assumptions like approximation of heat source as a point or disk-shaped (uniform) [2-8], constant heat flux radius $[2-8,10]$, constant thermal properties of work/tool materials $[2-8,10,13]$, the lack of applying PFE $[2-14,16]$, and calculating the exact value for energy distribution factor $[2-7,10-17]$. A need to eliminate these simplifying assumptions to make the model more realistic thus exists in order to accurately predict the shape and size of EDM-induced craters.

In the present paper, an effort has been made to simulate the EDM process considering more realistic assumptions. 
Fig. 1 a Schematic representation of heat flux applied on the cathode. $\mathbf{b}$ Portion of workpiece chosen for analysis

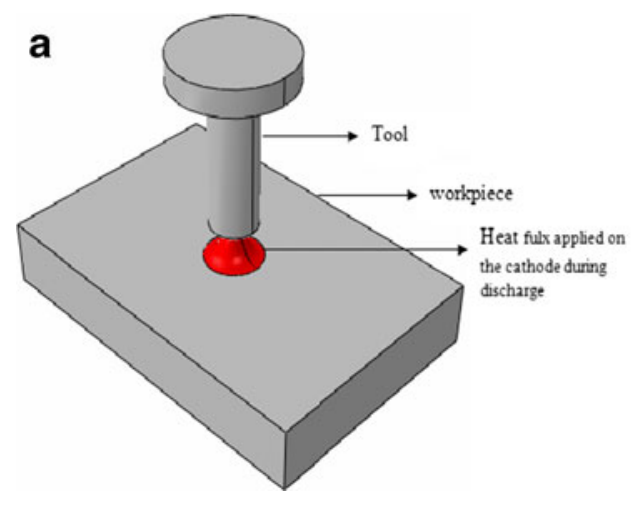

b

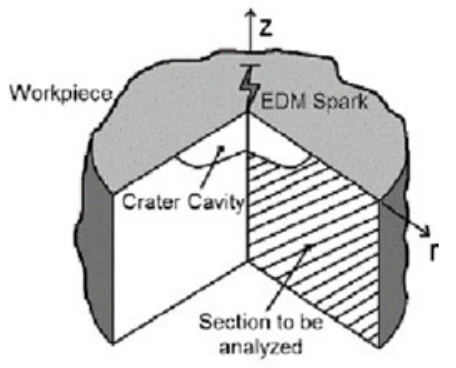

ANSYS finite element code has been used to develop a numerical model of the EDM process. After analyzing and solving the model, we have managed to govern the heat distribution on the workpiece (cathode). Calculated heat distribution has been used to obtain MRR. In order to investigate the accuracy of the predicted MRR, numerous experiments have been done at Arman Sanat die and mold manufacturing company. In addition to the conducted experiments, some comparisons are also made with data available in the literature. Comparing numerical and experimental data allowed us to precisely predict the energy distribution factor for AISI H13 tool steel which was used in this study. Using the developed model, the effect of the EDM parameters on MRR has been investigated by using the techniques of design of experiments (DOE) and response surface methodology (RSM). A quadratic polynomial regression model has been proposed for MRR and the accuracy of this model has been checked by means of the analysis of residuals.

\section{Thermal modeling of the EDM process}

\subsection{EDM process}

Processes that use electric discharge phenomenon to remove material from the workpiece can be classified into three main categories: die sinking EDM, milling EDM, and wire EDM (wire cut). In die sinking EDM, which has been considered in this paper, two electrodes (tool and the workpiece) are closely fixed inside a liquid dielectric medium. A voltage up to $200 \mathrm{~V}$ is applied between the electrodes generating, a high-density electric field which results in the ionization of dielectric liquid
Fig. 2 Axisymmetric model for EDM simulation and boundary conditions

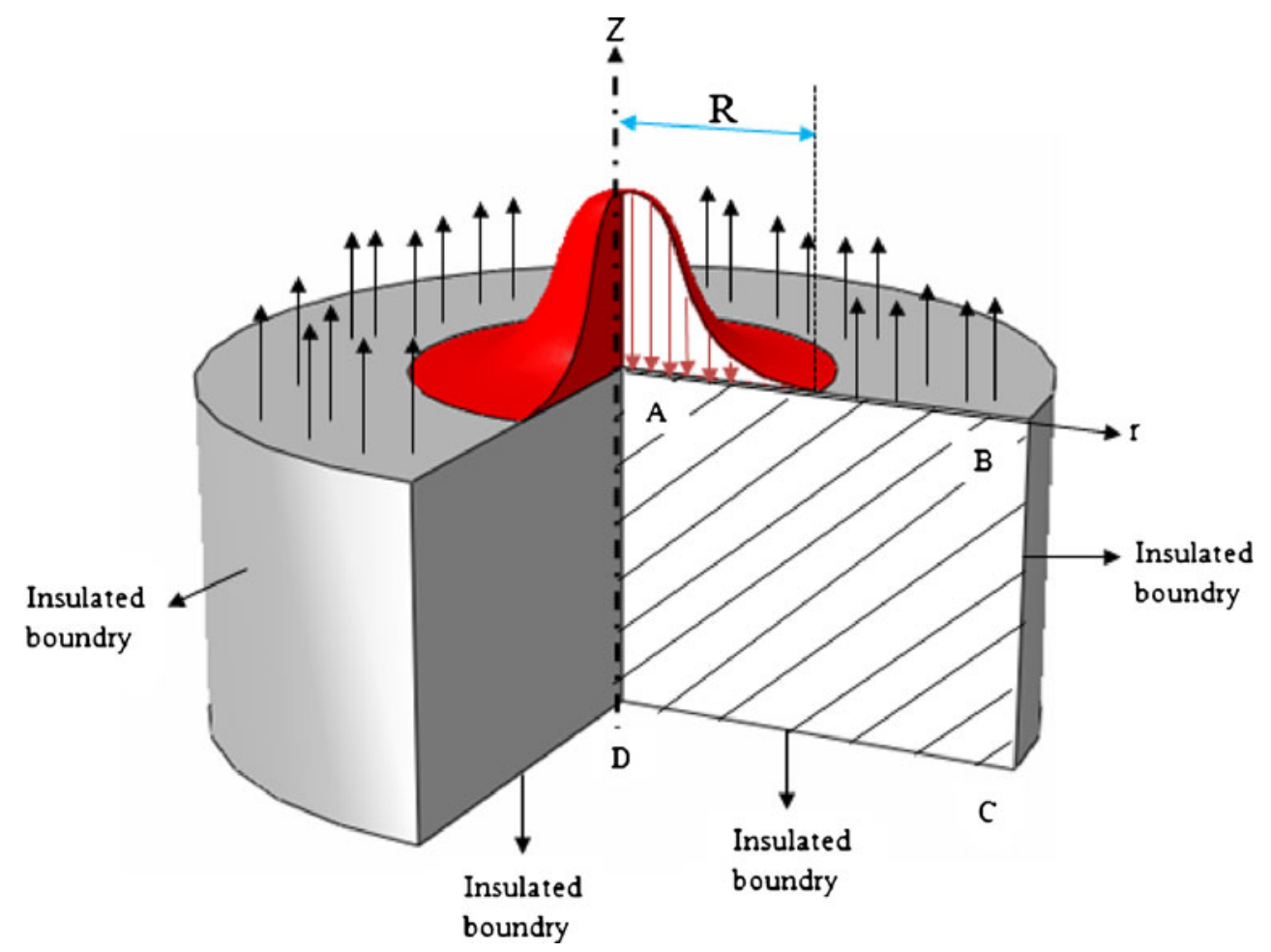


Table 1 Thermal properties of AISI H13 tool steel

\begin{tabular}{llll}
\hline Temperature (K) & $\begin{array}{l}\text { Thermal conductivity } \\
(\mathrm{W} / \mathrm{m} . \mathrm{K})\end{array}$ & $\begin{array}{l}\text { Specific heat } \\
(\mathrm{J} / \mathrm{kg} \mathrm{K})\end{array}$ & $\begin{array}{l}\text { Density, } \\
\left(\mathrm{kg} / \mathrm{m}^{3}\right)\end{array}$ \\
\hline 293 & 24.3 & 460 & 7,800 \\
773 & 27.7 & 550 & 7,640 \\
873 & 27.5 & 590 & 7,600 \\
\hline
\end{tabular}

Melt temperature $1,727 \mathrm{~K}$; latent heat of fusion $2.8 \times 10^{5} \mathrm{~J} / \mathrm{kg}$

in the closest distance between electrodes due to the created electric field and lets the electrons fall down from the cathode to the anode. Thus, the plasma channel is generated, and it has enough energy to melt and even vaporize the workpiece and tool material [12]. Upon finishing the pulse on-time, plasma pressure diminishes, which allows the dielectric fluid to wash away the molten material from the EDM-induced crater. During this process, a small amount of molten material is washed away according to PFE, and the remaining material resolidifies and makes the recast layer in the crater. During the EDM process, numerous discharges happen in a regularly timed manner, and each spark produces a small crater on the workpiece. A combination of these craters forms the desired shape on the workpiece. During each discharge, heat flux is applied on the workpiece where the inter-electrode gap is minimum (Fig. 1a), which can be used to model and simulate the EDM process. Assuming the nature of these sparks to be the same, we can model one of them and extend it to all the sparks that happen during the process $[14,16]$. A small cylindrical portion of the workpiece around the spark is chosen for analysis, which is shown in Fig. 1 b.

\subsection{Assumptions}

The machining mechanism of EDM is complex as it involves numerous phenomena such as heat conduction and radiation, phase changes, electrical forces, bubble formation, and collapse and rapid solidification; therefore some simplifying assumptions are used as follows:

1. The model is developed for a single spark.

2. It is assumed that the shape of the elements is not affected by thermal expansion [14].

3. The workpiece is free from any type of stress before the EDM process [14].

4. Conduction is considered as the mode of heat transfer to the electrodes [19].

5. The work domain is axisymmetric about the $Z$ axis.

6. Workpiece and tool material are homogeneous and isotropic in nature.

7. PFE is a function of pulse current and pulse on-time [17].

\subsection{Governing equations}

Since the model is axisymmetric, we can consider the Fourier heat conduction equation independent of circumferential condition as the differential equation which is given by:

$$
\frac{1}{r} \frac{\partial}{\partial r}\left(k r \frac{\partial T}{\partial r}\right)+\frac{\partial}{\partial z}\left(k \frac{\partial T}{\partial z}\right)=\rho C_{\mathrm{p}} \frac{\partial T}{\partial t}
$$

Fig. 3 Schematic of temperature distribution on the cathode
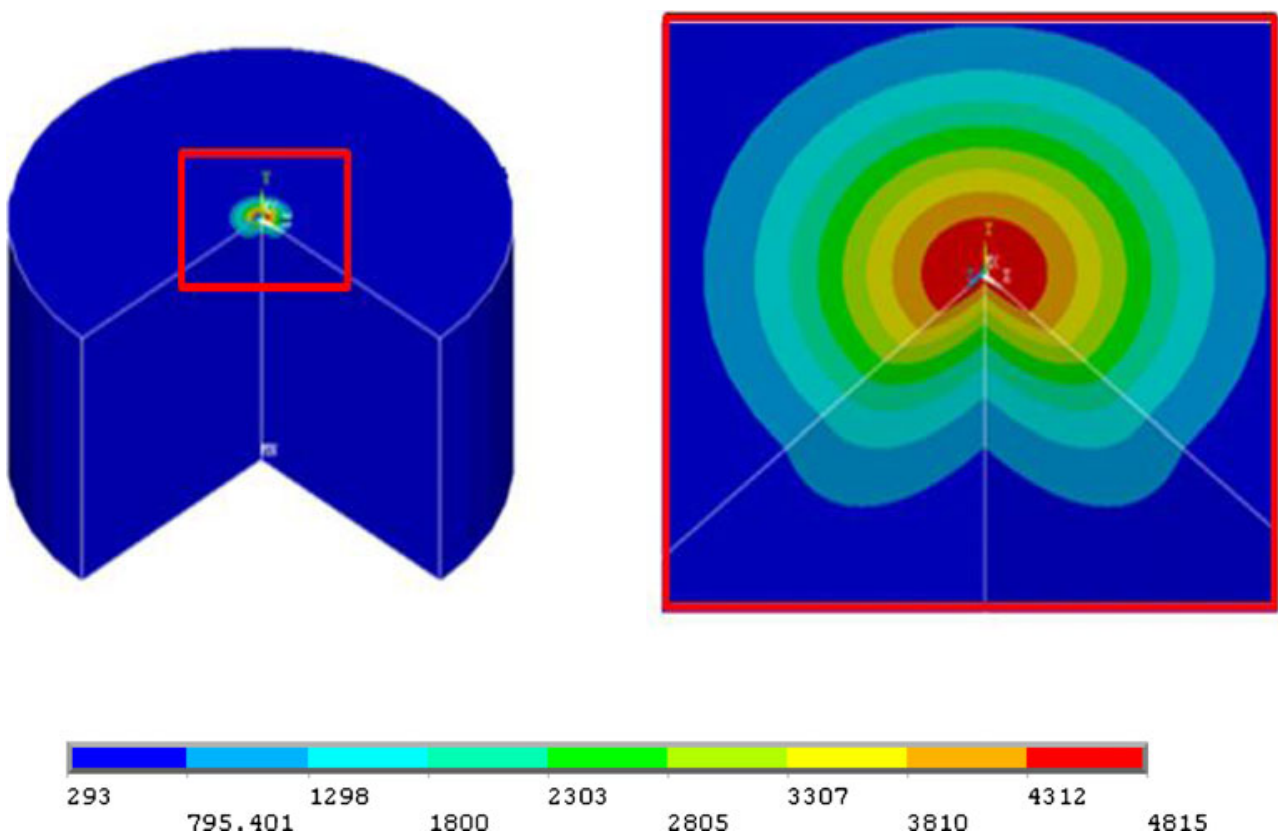
Table 2 EDM parameters used in the analysis

\begin{tabular}{llll}
\hline Levels & $I(\mathrm{~A})$ & $T_{\text {on }}(\mu \mathrm{s})$ & $V(\mathrm{v})$ \\
\hline Level 1 & 5 & 25 & 50 \\
Level 2 & 10 & 50 & 65 \\
Level 3 & 20 & 100 & 80 \\
Level 4 & 30 & 300 & - \\
Level 5 & 40 & 500 & - \\
\hline
\end{tabular}

$I$ discharge current, $T_{\text {on }}$ pulse on-time, $V$ discharge voltage

where $T$ is temperature $(K), t$ is time $(s), \rho$ is density $\left(\frac{\mathrm{kg}}{\mathrm{m}^{3}}\right), k$ is thermal conductivity $\left(\frac{\mathrm{w}}{\mathrm{mK}}\right), C_{\mathrm{p}}$ is specific heat capacity of workpiece material in solid state $\left(\frac{\mathrm{J}}{\mathrm{kg} \mathrm{K}}\right)$, and $r$ and $Z$ denote coordinate axis as shown in Fig. $1 \mathrm{~b}$.

\subsection{Boundary and initial conditions}

Figure 2 illustrates the assumed boundary conditions for the model. On the top surface, the heat transferred to the workpiece during the spark on-time is represented by a Gaussian heat flux distribution. Heat loss to the dielectric is modeled using convective boundary conditions on surface $\mathrm{AB}$. No heat transfer occurs across surfaces $\mathrm{AD}, \mathrm{BC}$, and $\mathrm{DC}$ as they are either symmetry line or boundary in the far distance, and the initial temperature is equal to dielectric temperature. In mathematical terms, the applied boundary and initial conditions are represented by Eqs. 2 and 3:

$$
\begin{aligned}
& \left\{\begin{array}{c}
k^{\partial T} / \partial z=Q_{\mathrm{w}}^{\prime \prime}(r) \text { if } 0 \leq r \leq R \text { on } A B \\
k^{\partial T} / \partial z=h\left(T-T_{0}\right) \text { if } r>R \text { on } A B \\
\partial T / \partial n=0 \text { for boundries } A D, B C, D C
\end{array}\right. \\
& T(t=0)=T_{0}
\end{aligned}
$$

where $Q_{\mathrm{w}}^{\prime \prime}(r)\left(\frac{\mathrm{w}}{\mathrm{m}^{2}}\right)$, is the heat flux applied to the workpiece during the pulse on-time and it has a zero magnitude during the pulse off-time. $R(m)$ is the spark radius, $h\left(\frac{\mathrm{w}}{\mathrm{m}^{2} \mathrm{~K}}\right)$ is the heat transfer coefficient for the dielectric fluid, and $T_{0}(\mathrm{~K})$ is the dielectric temperature at the beginning of the EDM process.

\subsection{Spark radius}

It is obvious that the size of the plasma channel does not remain constant during discharge but grows with time. Its growth depends on various parameters such as electrode material, pulse current, pulse on-time, and polarity. Different equations have been reported by researchers to identify how spark radius grows during pulse on-time $[8$, $18,20]$. From literature survey and as reported by several researchers $[16,17,25]$, a semi-empirical equation (Eq. 4) proposed by Ikai and Hashiguchi [18] which gives the spark radius as a function of current and pulse on-time can be used as an effective relation for the modeling of the growth of the plasma channel:

$R=\left(2.04 e^{-3}\right) I^{0.43} T_{\text {on }}{ }^{0.44}$

where $I(\mathrm{~A})$ is the pulse current and $T_{\mathrm{on}}(\mathrm{s})$ is pulse on-time.

\subsection{Heat distribution}

The type of heat flux applied onto the model as a heat source is one of the most important factors in the simulation process as it directly affects the accuracy of the results. Most of the previous researchers assumed two types of heat fluxes for their models: point heat source and uniformly distributed heat flux [2-8], but none of them can be true since the energy density of the sparks is not uniform in different radii of the plasma channel during discharge. Thus, the nature of
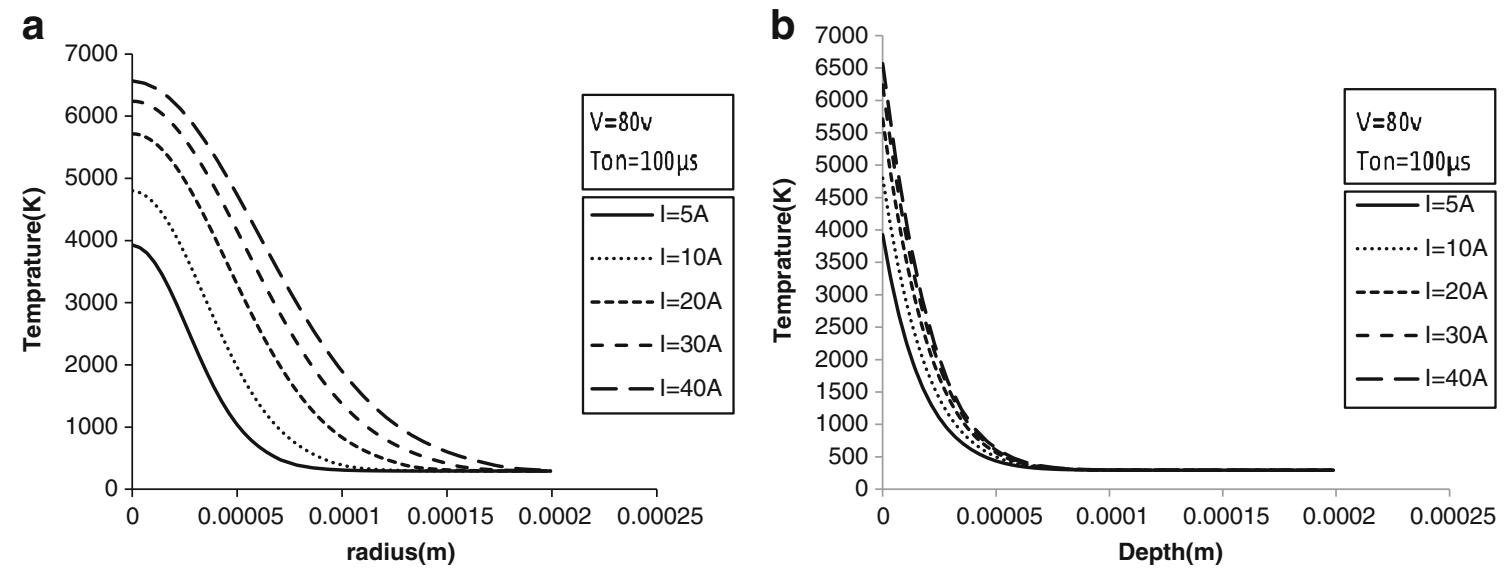

Fig. 4 Effect of pulse current on heat distribution: a across the radius of the workpiece, $\mathbf{b}$ in depth of the workpiece 

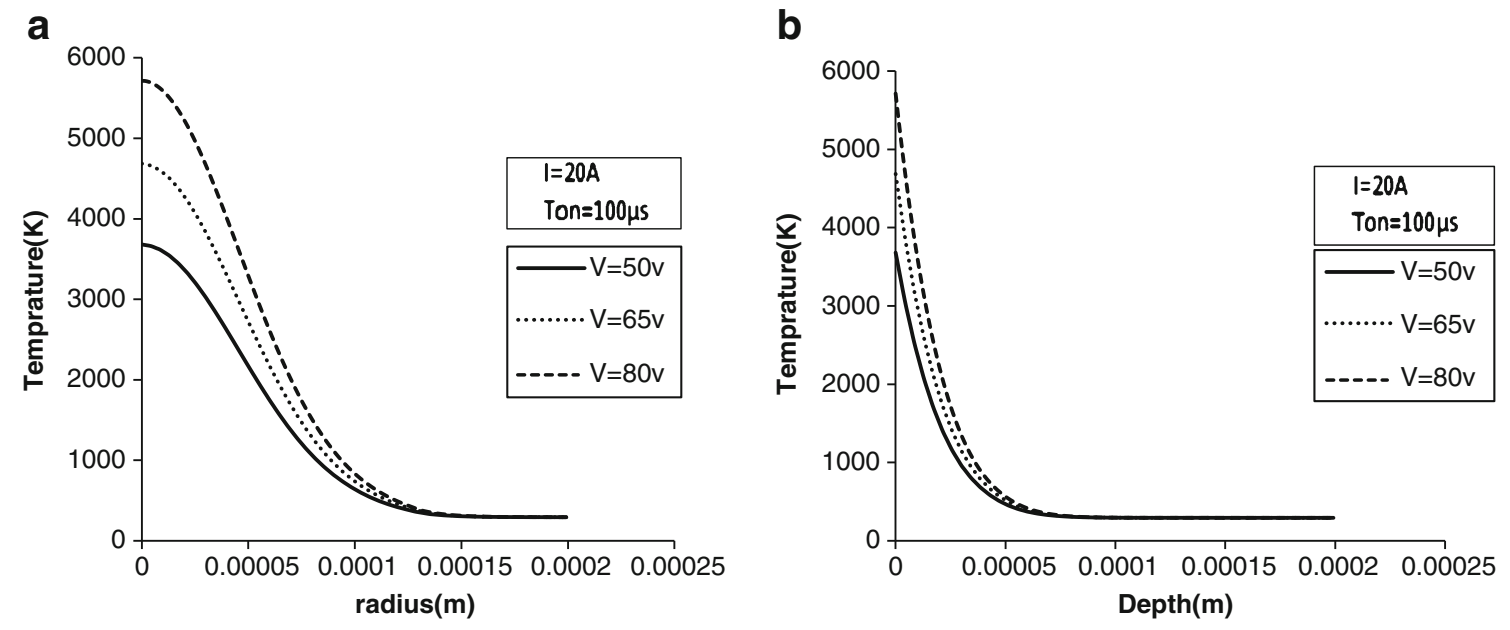

Fig. 5 Effect of pulse voltage on heat distribution: a across the radius of the workpiece, $\mathbf{b}$ in depth of the workpiece

the EDM process and sparks necessitates using Gaussian distribution for heat flux. The probability density function of Gaussian distribution for a random variable $r$ is given by Eq. 5 [22]:

$P(r)=\frac{1}{\sigma \sqrt{2 \pi}} e^{-\frac{r^{2}}{2 \sigma^{2}}}$

The domain of distribution can be restricted to $[-3 \sigma, 3 \sigma]$ with high reliability [22], where $\sigma$ is the standard deviation. So, if we replace $\sigma$ by $\frac{R}{3}$, we have:

$P(r)=\frac{3}{R \sqrt{2 \pi}} e^{-4.5\left(\frac{r^{2}}{R^{2}}\right)}$

Assuming $P(r)=Q_{\mathrm{w}}^{\prime \prime}(r)$ and $Q_{0}=\frac{3}{R \sqrt{2 \pi}}$, we can rewrite Eq. 6 as the following, where $Q_{0}$ is the maximum intensity of heat applied at the center of the workpiece:

$Q_{\mathrm{w}}^{\prime \prime}(r)=Q_{0} e^{-4.5\left(\frac{r^{2}}{R^{2}}\right)}$
Since the heat flux is distributed on the surface, the energy incident on the workpiece is:

$$
\begin{aligned}
\oint Q_{\mathrm{w}}^{\prime \prime}(r) d A & =\int_{0}^{R} Q_{\mathrm{w}}^{\prime \prime}(r) 2 \pi r d r \rightarrow \int_{0}^{R} Q_{0} e^{-4.5 \cdot\left(\frac{r^{2}}{R^{2}}\right)} 2 \pi r d r \\
& =0.2191 \pi Q_{0} R^{2}
\end{aligned}
$$

The equation that was governed for heat flux should be equal with the power applied on the workpiece, so we can write:

$F_{\mathrm{c}} V I=0.2191 \pi Q_{0} R^{2} \rightarrow Q_{0}=\frac{4.57 F_{\mathrm{c}} V I}{\pi R^{2}}$

Upon substitution of Eq. 9 into Eq. 7, the final equation for the heat flux will be:

$Q_{\mathrm{w}}^{\prime \prime}(r)=\frac{4.57 F_{\mathrm{c}} V I}{\pi R^{2}} e^{-4.5\left(\frac{r^{2}}{R^{2}}\right)}$
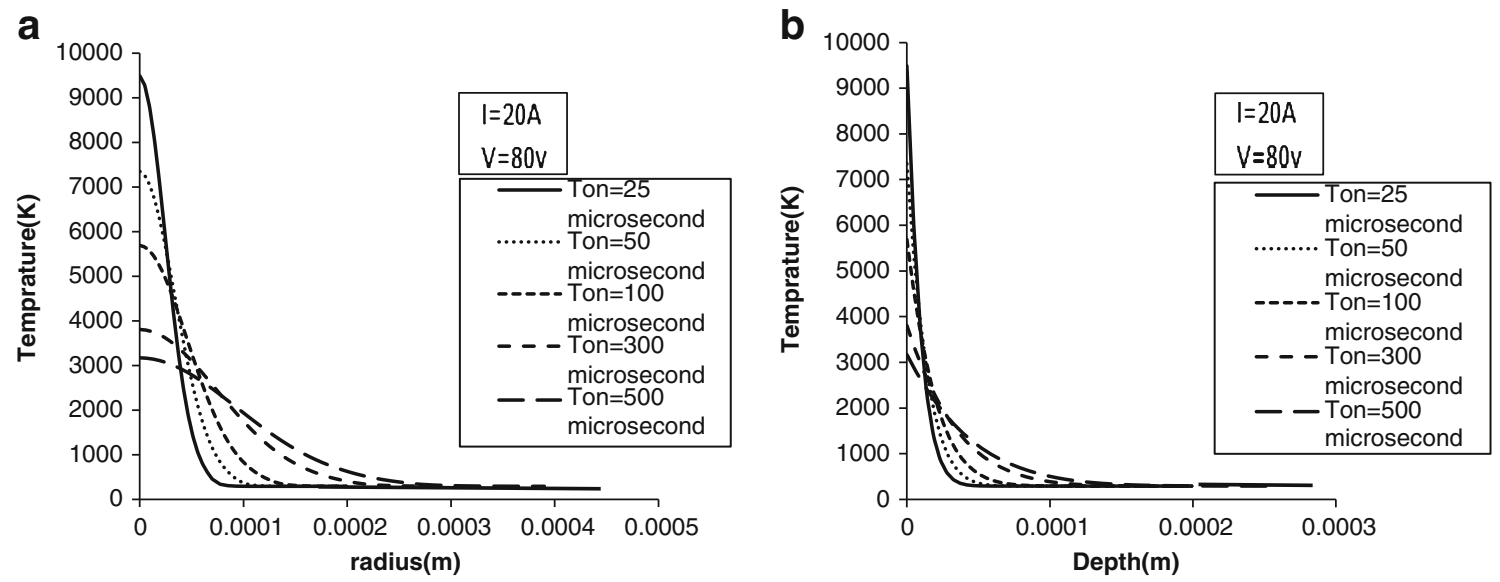

Fig. 6 Effect of pulse on-time on heat distribution: a across the radius of the workpiece, $\mathbf{b}$ in depth of the workpiece 

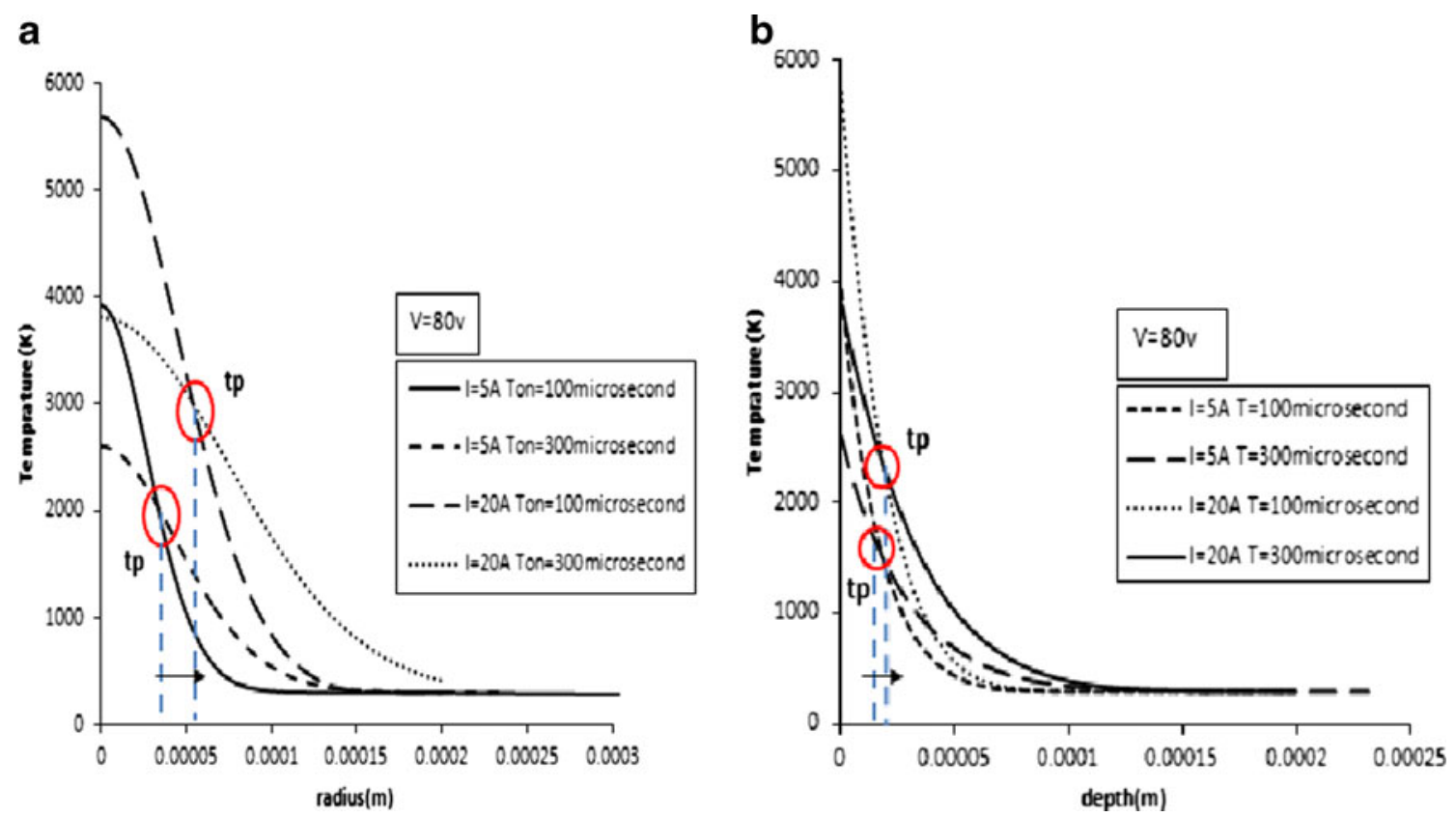

Fig. 7 Interactive effect of pulse current and pulse on-time on heat distribution: a across the radius of the workpiece, $\mathbf{b}$ in depth of the workpiece

where $F_{\mathrm{c}}$ is the percentage of energy absorbed by the workpiece (cathode), $V(\mathrm{~V})$ is the discharge voltage, and $I(\mathrm{~A})$ is the discharge current.

\subsection{Energy distribution factor $\left(F_{\mathrm{c}}\right)$}

When the discharge takes place between two electrodes, a large amount of energy is released, but only a fraction of this energy is absorbed by the workpiece and the rest is utilized to ionize dielectric liquid or melt and vaporize the tool specimen (anode). The percent of energy absorbed by the workpiece is called energy distribution factor, and it is denoted by $F_{\mathrm{c}}$. A few investigations have been done to precisely determine $F_{\mathrm{c}}$ values. For instance, Dibitonto et al. [8] performed EDM simulations in various operating conditions, and by comparing the experimental and analytical results, they arrived at an $F_{\mathrm{c}}$ value of 0.183 , where the best correlation between analytical and experimental results has been attained. Shanker et al. [11] arrived at a conclusion that about $40-45 \%$ of the heat input is absorbed by the workpiece. However, all of the calculations were made using water as the dielectric fluid. Since the capability of materials in absorbing energy is different, these values cannot be generalized. One of the main goals of this study is to a

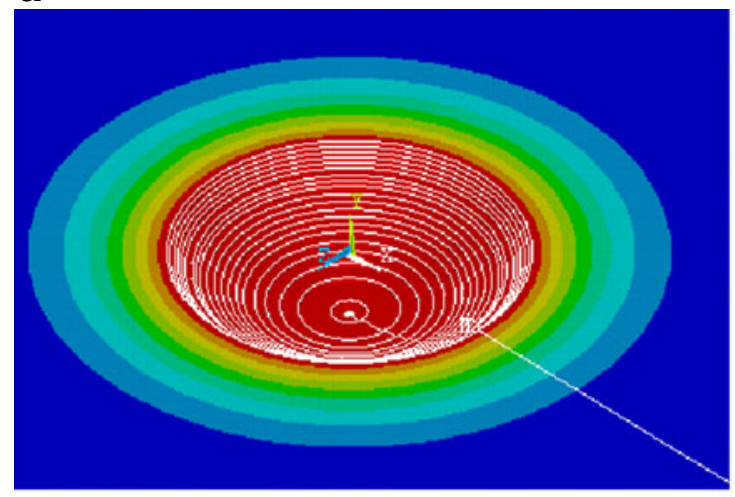

b

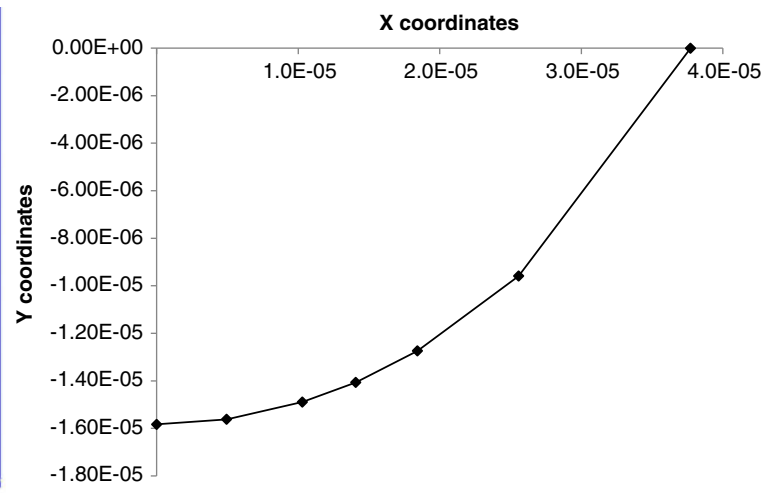

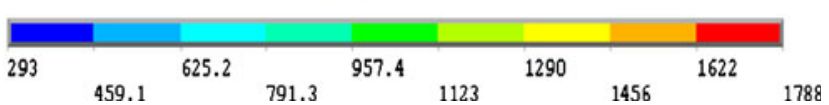

Fig. 8 a 3D shape of predicted crater. b Isothermal melt line of AISI H13 tool steel 

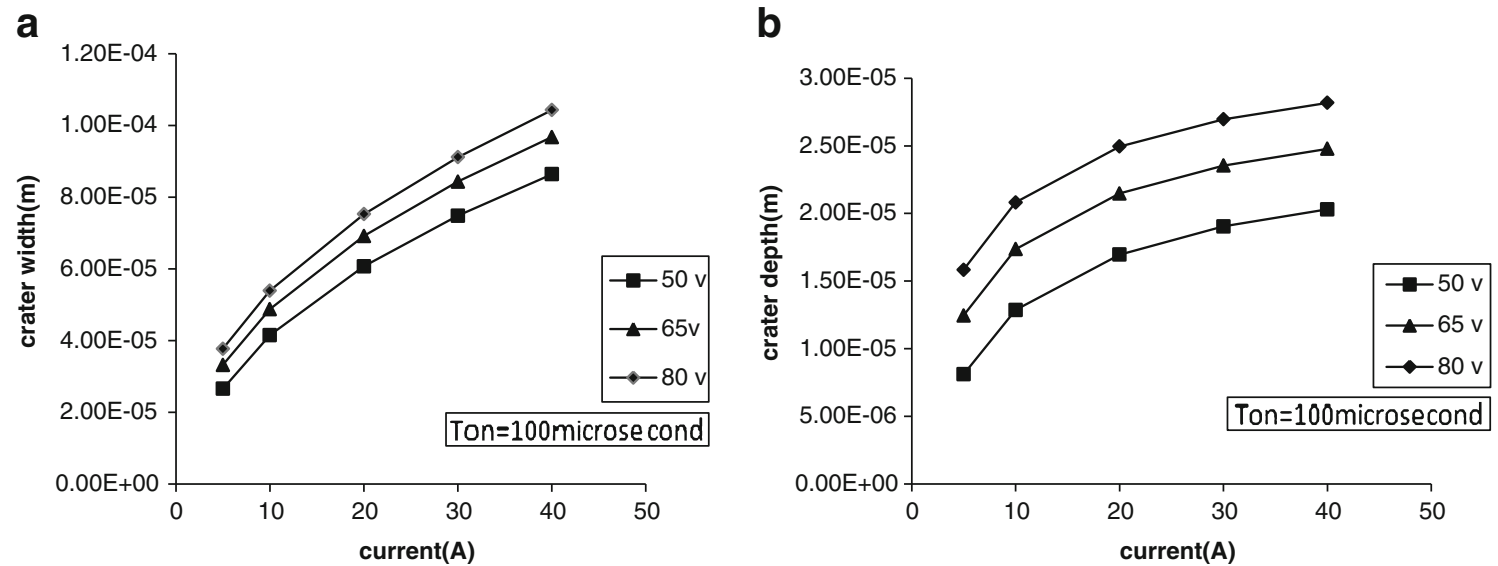

Fig. 9 Effect of pulse current and voltage on crater size: $\mathbf{a}$ on crater width, $\mathbf{b}$ on crater depth

obtain a true value of $F_{\mathrm{c}}$ for AISI H13 tool steel, which is known as the workhorse of die and mold industries. Thermal properties of AISI H13 tool steel are shown in Table 1.

\subsection{Phase change}

Energy released during discharge generates enough heat to melt and even vaporize the workpiece, so the latent heat changes during martensitic transformation and solidification take place over finite temperature intervals and can be presented by an equivalent temperature distribution of free enthalpy. Since the enthalpy $H\left(\frac{\mathrm{J}}{\mathrm{kg}}\right)$ and heat capacity $C$ $\left(\frac{\mathrm{J}}{\mathrm{kg} \mathrm{K}}\right)$ are related by Eq. 11, the latent heat effects of the phase changes can be incorporated in the form of an equivalent increase of the heat capacity in the form of Eq. 12:

$\Delta H(T)=\int_{T 1}^{T 2} C(T) d T$
$C_{\mathrm{pef} f}=C_{\mathrm{p}}+{ }^{\mathrm{LH}} /_{\Delta T}, \Delta T=T_{m}-T_{0}$

In these equations, $\mathrm{LH}\left(\frac{\mathrm{J}}{\mathrm{kg}}\right)$, is the latent heat of fusion, $T_{\mathrm{m}}$ is the melting temperature of AISI H13 tool steel, and $T_{0}$ is the dielectric temperature at the beginning of the machining process. Because of the high pressure during heating in plasma channel, very little amount of material evaporates, so we can neglect the phase change of liquid to vapor $[10,12$, $13,17,25-27]$.

\section{Solution methodologies}

The differential equation with boundary and initial conditions outlined earlier was solved by FEM method. Equations 13 to 23 show the methodology and procedure of solving Fourier heat conduction equation (Eq. 1) by FEM method. Using the general procedure, the total volume of the axisymmetric domain is discretized into finite elements. In each element, the temperature distribution $\left(T^{e}\right)$ is

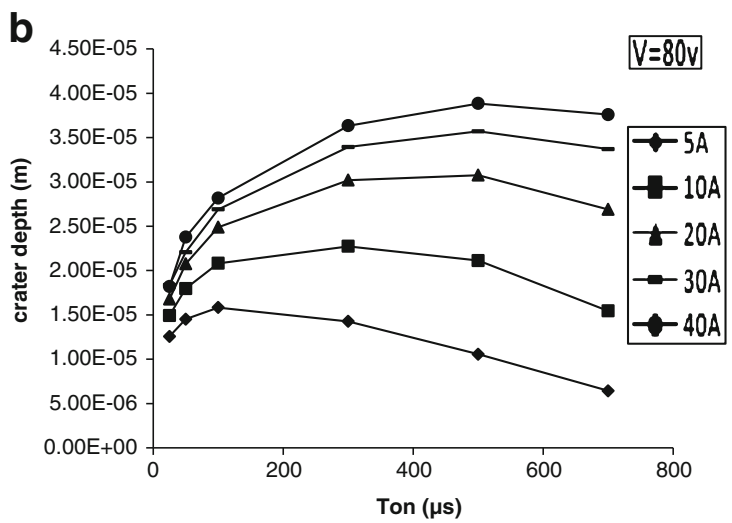

Fig. 10 Effect of pulse on-time on crater size: $\mathbf{a}$ on crater width, $\mathbf{b}$ on crater depth 


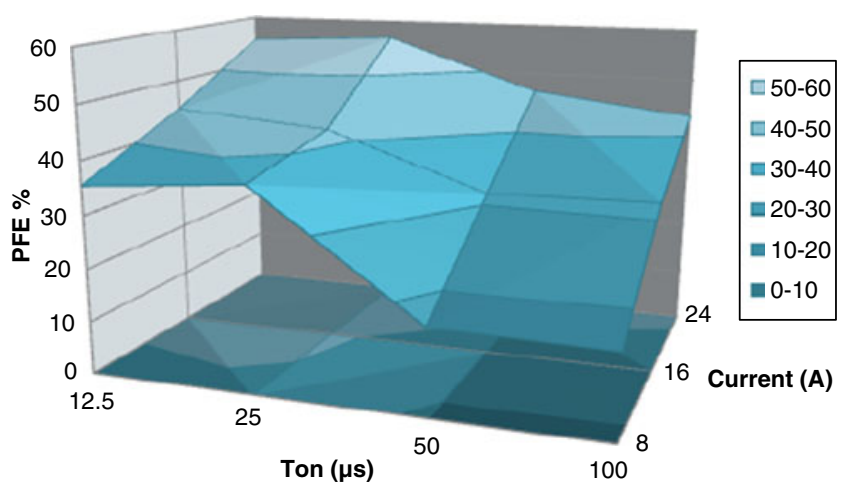

Fig. 11 Effect of pulse on-time and pulse current on PFE

expressed in terms of the nodal temperatures $\left(T_{i}\right)$ and interpolation functions $\left(N_{i}\right)$ as:

$T^{e}(x, y)=\sum_{i=1}^{M} N_{i}(x, y) T_{i}=[N][T]$ where $M$ is the number of nodes in an element. The interpolation functions vary with radial coordinate $r$ and axial coordinate $Z$. Application of Galerkin's method using Eq. 14 yields the residual equation (Eq. 15):

$$
\begin{gathered}
\iiint N_{i} R^{e} d V=0, \quad i=1, M \\
R^{e}=\frac{1}{r} \frac{\partial}{\partial r}\left(k r \frac{\partial T}{\partial r}\right)+\frac{\partial}{\partial z}\left(k \frac{\partial T}{\partial z}\right)-\rho C_{\mathrm{p}} \frac{\partial T}{\partial t} \\
2 \pi \iint N_{i}\left[k \frac{\partial}{\partial r}\left(r \frac{\partial T}{\partial r}\right)+k \frac{\partial}{\partial z}\left(r \frac{\partial T}{\partial z}\right)-\rho r C_{\mathrm{p}} \frac{\partial T}{\partial t}\right] d r d z \\
=0, i=1, M
\end{gathered}
$$

Applying chain rule of differentiation (Eq. 16 and 17), one can rewrite Eq. 15 like Eq. 18:

$\frac{\partial}{\partial r}\left(r N_{i} \frac{\partial T}{\partial r}\right)=N_{i} \frac{\partial}{\partial r}\left(r \frac{\partial T}{\partial r}\right)+r \frac{\partial T}{\partial r} \frac{\partial N_{i}}{\partial r} \rightarrow N_{i} \frac{\partial}{\partial r}\left(r \frac{\partial T}{\partial r}\right)=\frac{\partial}{\partial r}\left(r N_{i} \frac{\partial T}{\partial r}\right)-r \frac{\partial T}{\partial r} \frac{\partial N_{i}}{\partial r}$

$\frac{\partial}{\partial z}\left(r N_{i} \frac{\partial T}{\partial z}\right)=N_{i} \frac{\partial}{\partial z}\left(r \frac{\partial T}{\partial z}\right)+r \frac{\partial T}{\partial z} \frac{\partial N_{i}}{\partial z} \rightarrow N_{i} \frac{\partial}{\partial z}\left(r \frac{\partial T}{\partial z}\right)=\frac{\partial}{\partial z}\left(r N_{i} \frac{\partial T}{\partial z}\right)-r \frac{\partial T}{\partial z} \frac{\partial N_{i}}{\partial z}$

$2 \pi \iint_{k}\left[\frac{\partial}{\partial r}\left(r N_{i} \frac{\partial T}{\partial r}\right)+\frac{\partial}{\partial z}\left(r N_{i} \frac{\partial T}{\partial z}\right)\right] d r d z-2 \pi \iint k\left(\frac{\partial T}{\partial r} \frac{\partial N_{i}}{\partial r}+\frac{\partial T}{\partial z} \frac{\partial N_{i}}{\partial z}\right) d r d z$

$-2 \pi \iint N_{i} r \rho c_{\mathrm{p}} \frac{\partial T}{\partial t} d r d z=0$

Fig. 12 Compression of MRR between our model and Dibitono's model

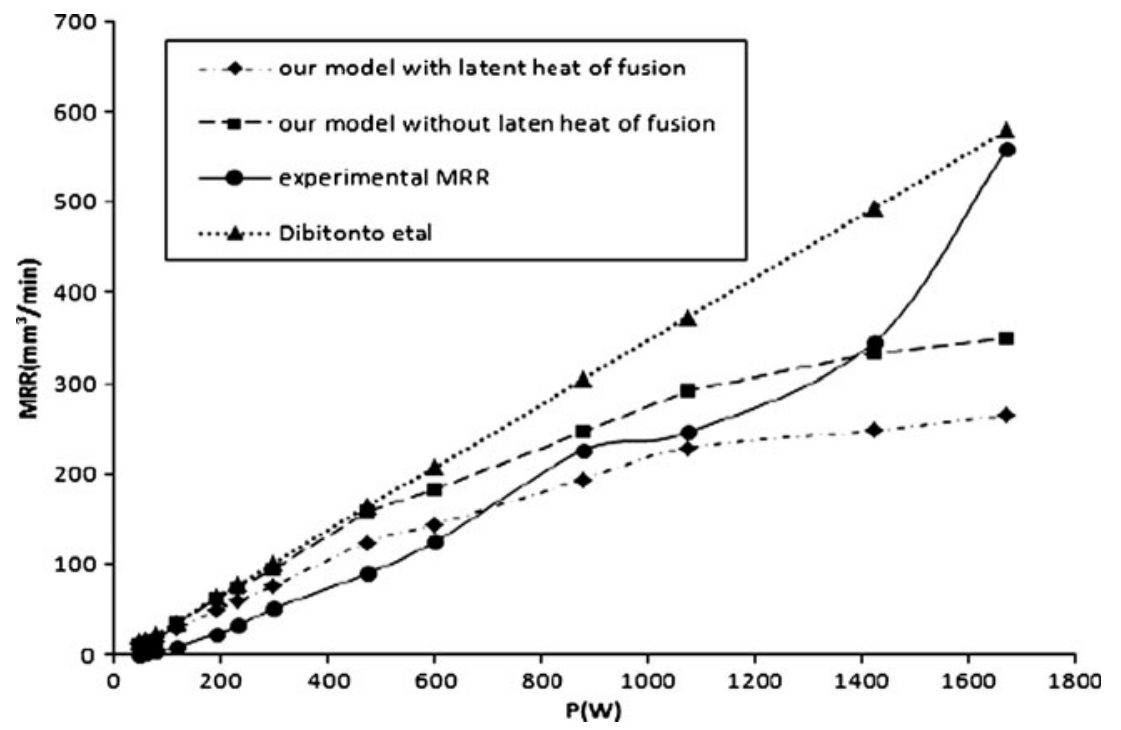


Table 3 Results for theoretical MRR

\begin{tabular}{|c|c|c|c|c|c|c|c|c|c|c|}
\hline \multicolumn{7}{|l|}{ Machining condition } & \multicolumn{4}{|c|}{ Theoretical MRR $\left(\frac{\mathrm{mm}^{3}}{\mathrm{~min}}\right)$} \\
\hline Experiment number & $I(\mathrm{~A})$ & $\mathrm{V}(\mathrm{v})$ & $T_{\text {on }}(\mu \mathrm{s})$ & $T_{\text {off }}(\mu \mathrm{s})$ & $\mathrm{P}(\mathrm{W})$ & $\mathrm{PFE} \%$ & $F_{\mathrm{c}}=0.18$ & $F_{\mathrm{c}}=0.15$ & $F_{\mathrm{c}}=0.1$ & $F_{\mathrm{c}}=0.05$ \\
\hline 1 & 5 & 80 & 10 & 10 & 200 & 28.708 & 14.891 & 10.662 & 6.167 & 2.451 \\
\hline 2 & 5 & 80 & 25 & 10 & 285.71 & 20.686 & 38.925 & 25.255 & 15.572 & 4.676 \\
\hline 3 & 10 & 80 & 25 & 10 & 571.42 & 34.757 & 53.885 & 42.216 & 26.081 & 13.829 \\
\hline 4 & 15 & 80 & 50 & 10 & 1,000 & 36.920 & 126.062 & 92.269 & 55.228 & 27.38 \\
\hline 5 & 20 & 80 & 100 & 10 & $1,454.54$ & 36.850 & 215.277 & 146.86 & 84.490 & 50.764 \\
\hline 6 & 25 & 80 & 150 & 10 & 1,875 & 37.835 & 280.438 & 244.340 & 120.793 & 57.450 \\
\hline 7 & 30 & 80 & 200 & 10 & $2,285.71$ & 38.973 & 348.576 & 253.876 & 170.065 & 70.546 \\
\hline 8 & 35 & 80 & 300 & 10 & $2,709.67$ & 38.671 & 491.463 & 366.561 & 186.487 & 106.482 \\
\hline 9 & 40 & 80 & 450 & 10 & $3,130.43$ & 37.986 & 572.599 & 407.784 & 257.005 & 128.766 \\
\hline
\end{tabular}

The first integrand on the left-hand side of Eq. 18 is a perfect differential in two dimensions, and the Green-Gauss theorem can be applied to obtain Eq. 19:

$$
\begin{aligned}
-2 \pi \oint\left(q_{\mathrm{s}}^{\prime \prime} n_{\mathrm{s}}\right) r N_{i} d s= & 2 \pi \iint k\left(\frac{\partial T}{\partial r} \frac{\partial N_{i}}{\partial r}+\frac{\partial T}{\partial z} \frac{\partial N_{i}}{\partial z}\right) d r d z \\
& +2 \pi \iint N_{i} r \rho c_{p} \frac{\partial T}{\partial t} d r d z
\end{aligned}
$$

where $q_{\mathrm{s}}^{\prime \prime}$ is the heat flux entering the surface of the element and $n_{\mathrm{s}}$ is the normal vector of the surface.

Upon substituting Eq. 13 into Eq. 19, we will have:

$$
\begin{aligned}
& 2 \pi \iint k\left(\left[\frac{\partial N}{\partial r}\right]^{T}\left[\frac{\partial N}{\partial r}\right]\{T\}+\left[\frac{\partial N}{\partial z}\right]^{T}\left[\frac{\partial N}{\partial z}\right]\{T\}\right) d r d z \\
& +2 \pi \iint r \rho c_{\mathrm{p}}[N]^{T}[N]\{T\} d r d z=-2 \pi \oint\left(q_{\mathrm{s}}^{\prime \prime} n_{\mathrm{s}}\right) r[N]^{T} d s
\end{aligned}
$$

By defining $\left[k^{(e)}\right],\left[c^{(e)}\right]$, and $\left\{f_{\mathrm{g}}^{(e)}\right\}$ as element conductance matrix, capacitance matrix, and element forcing function, respectively, Eq. 20 can be rewritten in the following form:

$$
\begin{gathered}
{\left[k^{(e)}\right]\{T\}+\left[c^{(e)}\right]\{\dot{T}\}=\left\{f_{\mathrm{g}}^{(e)}\right\}} \\
{\left[k^{(e)}\right]=2 \pi \iint_{k}\left(\left[\frac{\partial N}{\partial r}\right]^{T}\left[\frac{\partial N}{\partial r}\right]+\left[\frac{\partial N}{\partial z}\right]^{T}\left[\frac{\partial N}{\partial z}\right]\right) d r d z} \\
{\left[c^{(e)}\right]=2 \pi \iint^{(e} r c_{\mathrm{p}}[N]^{T}[N] d r d z} \\
\left\{f_{\mathrm{g}}^{(e)}\right\}=-2 \pi \oint q_{\mathrm{s}}^{\prime \prime} n_{\mathrm{s}}[N]^{T} r d S
\end{gathered}
$$

Note that boundary gradient components are incorporated in the forcing function. Equation 21 is an ordinary firstorder differential equation and has not been converted to an algebraic one yet. So, we make use of finite difference method to discretize the time:

$$
\left[k^{(e)}\right]\{T(t)\}+\left[c^{(e)}\right]\left\{\frac{\{T(t+\Delta T)\}-\{T(t)\}}{\Delta t}\right\}=\left\{f_{\mathrm{g}}^{(e)}(t)\right\}
$$
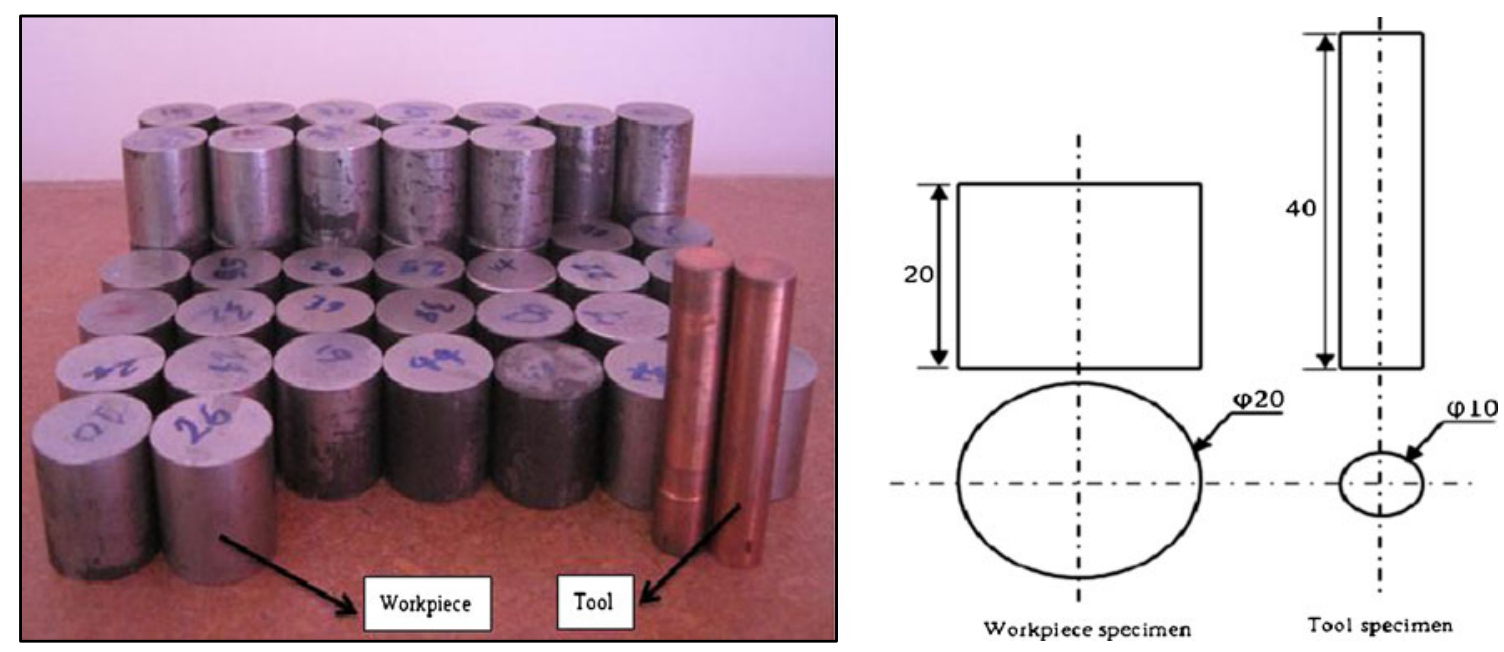

Fig. 13 Workpiece and tool specimens used in ED machining 
Fig. 14 a EDM machine used for machining. b Machined workpieces
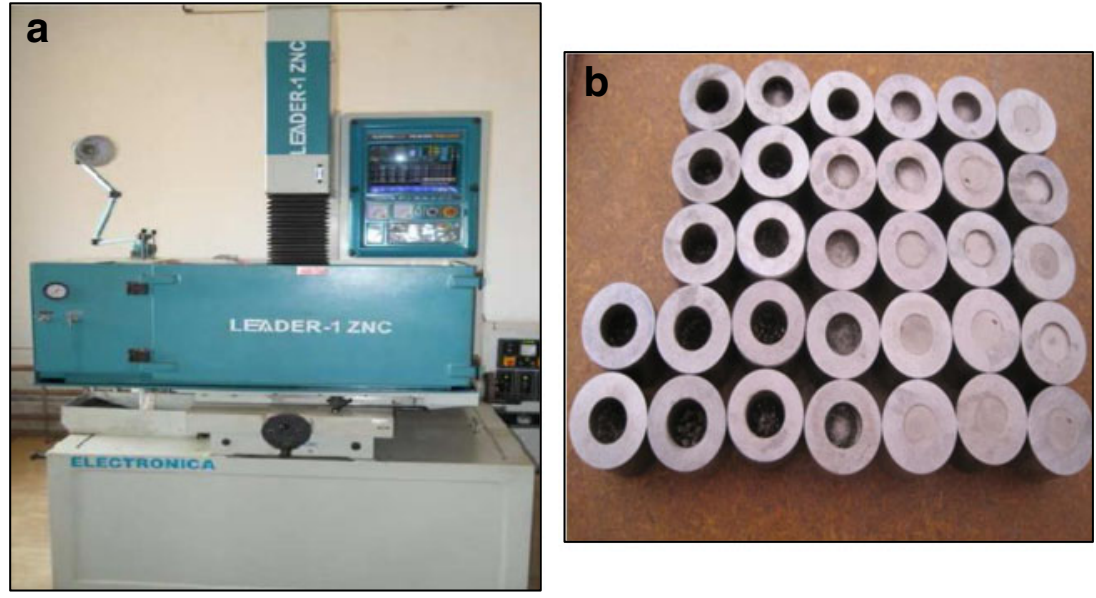

If the nodal temperatures are known at time $t$ and the forcing functions are evaluated at time $t$, Eq. 22 can be solved, algebraically, for the nodal temperatures at time $t+$ $\Delta t$. Denoting the time at the $i^{\text {th }}$ time step as $t_{i}=i(\Delta t), i=1,2$, $\ldots$, we can obtain:

$$
\begin{aligned}
{\left[c^{(e)}\right]\left\{T\left(t_{i+1}\right)\right\}=} & {\left[c^{(e)}\right]\left\{T\left(t_{i}\right)\right\}-[k]\left\{T\left(t_{i}\right)\right\} \Delta t } \\
& +\left\{f_{\mathrm{g}}^{(e)}\left(t_{i}\right)\right\} \Delta t
\end{aligned}
$$

To predict the temperature distribution at the end of each transient heat transfer cycle, ANSYS finite element code was used. Figure 3 illustrates the heat distribution on the model for EDM parameters of pulse on-time $=100 \mu \mathrm{s}$, discharge current $=10 \mathrm{~A}$, and discharge voltage $=80 \mathrm{~V}$. The following steps were taken to evaluate the heat distribution on the workpiece:

1. The primary value for energy distribution was set as 0.183 , and the heat flux and spark radius were calculated based on this value and machining conditions.

2. AISI H13 tool steel thermal characteristics such as density, specific heat, and conductivity were defined.

3. Geometry of the model was created. Since the model is axisymmetric, a two-dimensional $0.6 \times 0.6 \mathrm{~mm}$ geometry was defined.

4. Discretization of the domain has been done by mapped meshing technique using four node axisymmetric thermal solid element (PLANE55), and finer mesh was applied on the area which is affected by the heat flux (top left corner).

5. Heat flux and boundary conditions were applied on the model, and initial condition was set as the dielectric temperature.

6. Pulse on-time was defined as a time step, and this interval was discretized to 100 substeps.

7. Transient thermal analysis was carried out, and isothermal lines were extracted.

\section{Effect of EDM parameters on heat distribution}

In order to determine the effect of EDM parameters on heat distribution in the cathode, several machining parameters with different levels were selected as shown in Table 2.

Figure $4 a, b$ illustrates the effect of pulse current on heat distribution across the radius and through the depth of the workpiece for $\theta=0^{\circ}$, respectively. As shown in Fig. 4a, increasing the pulse current raises the temperature on the workpiece surface. This is because energy densities of pulses soar with an increase in the current. We can also conclude from this figure that increasing the current enlarges the area affected by the heat flux, which can be explained by the growth of the plasma channel's radius. Figure $4 \mathrm{~b}$ shows the effect of pulse current on temperature distribution through the depth of the workpiece (cathode). It is evident that larger values of current produce higher temperatures in the workpiece.

Figure 5a, b illustrates the effect of pulse voltage on heat distribution across the radius and through the depth of the workpiece in $\theta=0^{\circ}$, respectively. As shown, raising the pulse voltage increases the temperature in both directions, but it cannot enlarge the heat-affected zone on the surface of the workpiece since the radius of the plasma is independent of pulse voltage due to Hashiguchi's equation [18].

Table 4 Experimental test conditions

\begin{tabular}{ll}
\hline Generator type & Iso-pulse \\
Dielectric fluid & Oil flux ELF2 \\
Flushing type & Normal flushing \\
Power supply voltage $(\mathrm{V})$ & 200 \\
Reference voltage $(\mathrm{V})$ & 80 \\
Pulse current $(\mathrm{A})$ & $5,10,15,20,25,30,35,40$ \\
Polarity & Positive \\
Pulse on-time $(\mu \mathrm{s})$ & $10,25,50,100,150,200,300,450$ \\
Pulse off-time $(\mu \mathrm{s})$ & 10 \\
Tool material & Commercial pure copper \\
\hline
\end{tabular}


Table 5 Results for experimental MRR

\begin{tabular}{lllllllll}
\hline $\begin{array}{l}\text { Experiment } \\
\text { number }\end{array}$ & $I(\mathrm{~A})$ & $V(\mathrm{v})$ & $\mathrm{T}_{\text {on }}(\mu \mathrm{s})$ & $\mathrm{T}_{\text {off }}(\mu \mathrm{s})$ & $\mathrm{P}(\mathrm{W})$ & $\mathrm{M}_{1}(\mathrm{~g})$ & $\mathrm{M}_{2}(\mathrm{~g})$ & $\mathrm{MRR}_{\exp }\left(\frac{\mathrm{mm}^{3}}{\min }\right)$ \\
\hline 1 & 5 & 80 & 10 & 10 & 200 & 58.876 & 58.678 & 1.269 \\
2 & 5 & 80 & 25 & 10 & 285.71 & 58.906 & 58.604 & 1.935 \\
3 & 10 & 80 & 25 & 10 & 571.42 & 58.800 & 57.224 & 10.102 \\
4 & 15 & 80 & 50 & 10 & 1,000 & 58.940 & 55.138 & 24.371 \\
5 & 20 & 80 & 100 & 10 & $1,454.54$ & 58.820 & 51.976 & 43.871 \\
6 & 25 & 80 & 150 & 10 & 1,875 & 58.906 & 50.536 & 53.653 \\
7 & 30 & 80 & 200 & 10 & $2,285.71$ & 58.973 & 48.572 & 66.673 \\
8 & 35 & 80 & 300 & 10 & $2,709.67$ & 58.770 & 41.369 & 111.544 \\
9 & 40 & 80 & 450 & 10 & $3,130.43$ & 58.933 & 29.317 & 190.230 \\
\hline
\end{tabular}

The effect of pulse on-time on heat distribution is depicted in Fig. 6. Since the time for heat transfer increases by increasing pulse on-time, temperature and gradient of heat loss diminish in the workpiece and cause enlargement of the heat-affected zone. However, this can also be described by the growth of the radius of the plasma channel with increase of pulse on-time values.

Figure 7 a demonstrates the heat distribution across the radius for $\theta=0^{\circ}$. This figure is the combination of Figs. $4 \mathrm{a}$ and $6 \mathrm{a}$ for some machining conditions. It is clear from the figure that for a constant value of current, any increase in the pulse duration decreases the temperature along the surface of the workpiece, and as described earlier, it is because of increasing the duration of heat loss. On the other hand, increasing the pulse duration also decreases the gradient of heat loss since the area affected by the heat flux increases. So, a point emerges on the graphs in which the situation is reversed, and by increasing the pulse duration, the temperature rises, which has been shown by "tp". For example, assuming a current of $5 \mathrm{~A}$, it can be seen that by increasing the pulse duration from 100 to $300 \mu$ s, temperature diminishes from 3,900 to $2,500 \mathrm{~K}$ in the center of the workpiece $(r=0)$, which shows the reduction of about $35 \%$ and "tp" occurring at $r=30 \mu \mathrm{m}$. Using the same procedure and assuming a value of $20 \mathrm{~A}$ for current, it can be observed that the temperature decreases from 5,700 to $3,800 \mathrm{~K}$ in the center of the workpiece by increasing the pulse duration from 100 to $300 \mu$ s, which shows the reduction of $33 \%$; in this case, "tp" occurs at $r=60 \mu \mathrm{m}$, which is twice larger than the previous case. Hence, by comparing the two cases, it can be concluded that increasing the pulse current elevates the radius equal to "tp" and decreases the heat loss in the center of the workpiece, which happened by increasing the pulse duration.

By investigating the effect of pulse current on heat distribution and assuming a constant value for pulse duration, it can be recognized that in the pulse duration of $100 \mu \mathrm{s}$, increasing the current from 5 to $20 \mathrm{~A}$ raises the temperature from 3,900 to $5700 \mathrm{~K}$ in the center of the plasma channel $(r=0)$, which shows $46 \%$ increase. Repeating the same methodology for a
Fig. 15 Compression between our own theoretical and experimental MRR

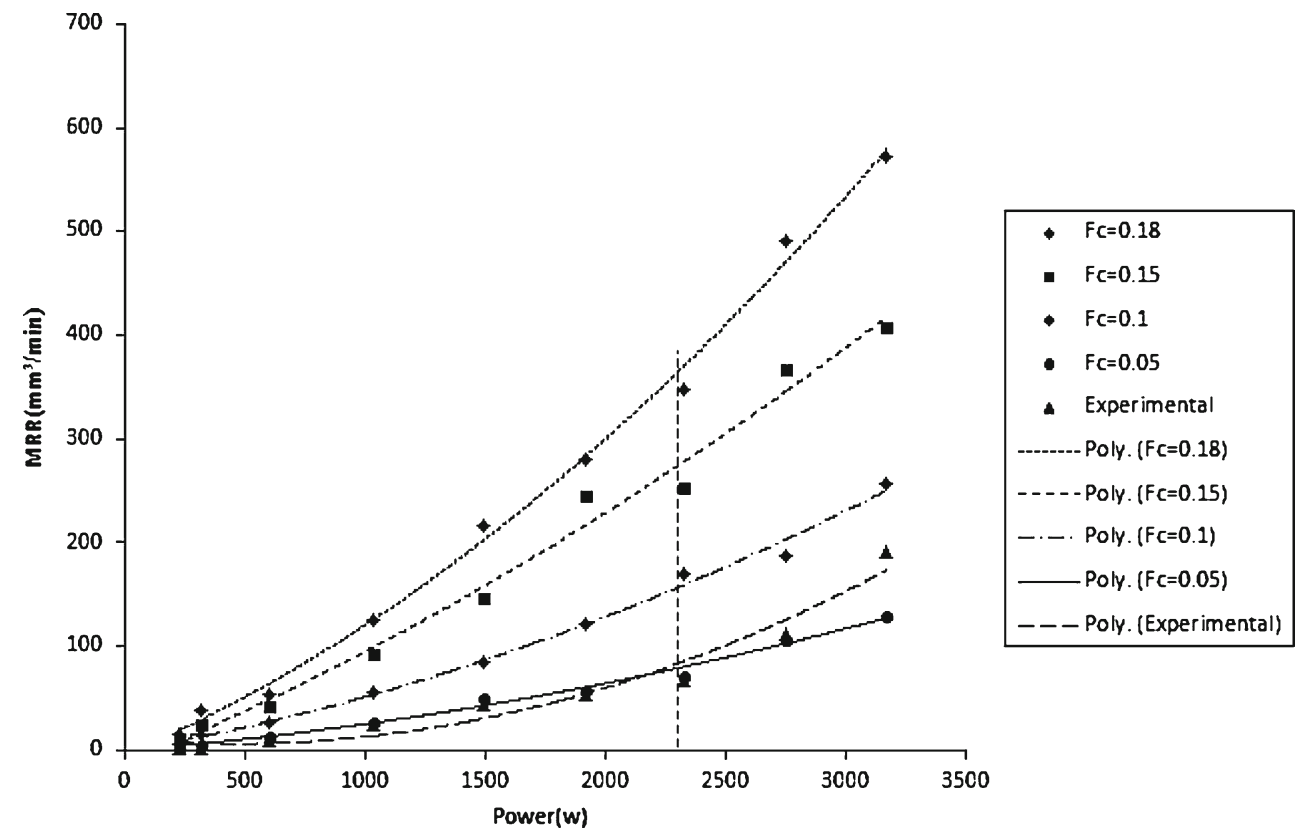


Fig. 16 Compression of MRR between our own model and Joshi's model

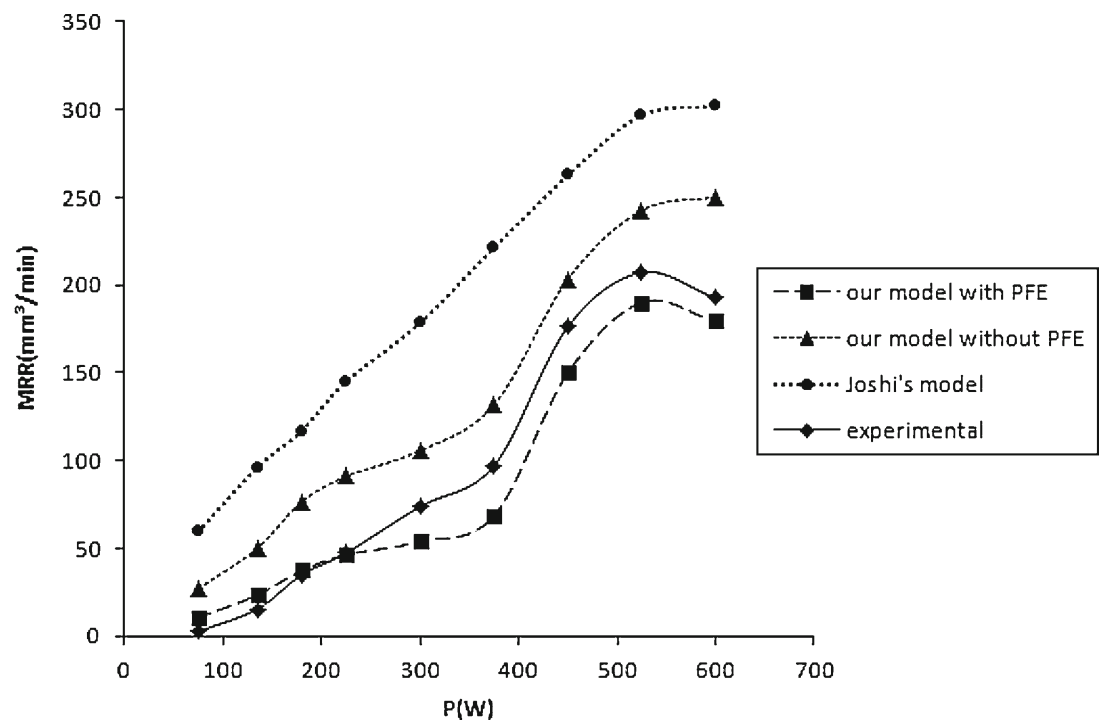

pulse duration of $300 \mu \mathrm{s}$, it can be seen that the temperature rises from 2,500 to $3,800 \mathrm{~K}$ at $r=0$, which shows an increase of about $52 \%$. From the preceding discussion, it can be concluded that any increase in the current boosts the temperature on the surface of the workpiece and higher values of pulse duration elevate the rate of temperature augmentation.

Figure $7 \mathrm{~b}$ illustrates heat distribution through the depth of the workpiece for different machining conditions. It is clear from the figure that the variation of heat distribution shows a similar trend to heat distribution across the radius of the workpiece which was discussed earlier. However, the effect of current on the location of "tp" is not substantial.

\section{MRR calculation}

\subsection{Theoretical MRR}

The first step in computing theoretical MRR is the calculation of crater volume. Electric discharges cause localized melting of the workpiece. The molten material is washed away by the dielectric fluid. The amount of material being washed away by the dielectric is influenced by PFE. The value of PFE depends on many parameters and is determined empirically. PFE was initially set equal to unity, and the temperature profiles obtained from FEM analysis were used to calculate the amount of material removed from the workpiece. In order to model the crater shape, element birth and death technique was used, and the model was updated excluding those elements whose temperature rose above the melting temperature for AISI H13 tool steel $(1,727 \mathrm{~K})$. Figure 8a illustrates the 3D shape of the crater.

To calculate the crater volume, isothermal melt line of $\mathrm{H} 13$ tool steel $(1,727 \mathrm{~K})$ was plotted, which is shown in Fig. 8 b, and by revolving it around the $Y$ axis, we were able to calculate the crater volume.
Effects of EDM parameters (presented in Table 2) on the shape and size of crater were also investigated. Figure 9a, b demonstrates the effect of pulse current and voltage on the radius and depth of crater, respectively. It is clear from these figures that increasing current and voltage enlarges the radius and depth of crater, which is due to the soaring energy density of pulses by increasing pulse current and voltage.

Figure 10a, b shows the effect of pulse on-time on crater size for different values of pulse current for a constant pulse voltage. In the low values of pulse on-time, crater radius shows an increasing trend but converges to a constant value as the time increases. Crater depth possesses a similar behavior for low values of time but attains a decreasing trend as the value of time exceeds a certain critical value. These trends extremely depend on the applied current and occur in a higher level for large currents since the increase in pulse current amplifies the discharge energy and plasma radius, which leads to the enlargement of the area affected by the heat flux and thereby increase of the crater radius and depth. The effect of pulse on-time on the crater size which was described earlier might be attributed to the fact that higher discharge durations generate lower flux densities, leading to less heat conduction along the axial and radial $(r-z)$ direction.

The second step in MRR calculations is to determine PFE. Theoretically, it is not possible to calculate PFE due to the lack of knowledge and engineering and analysis tools. Therefore, experiment-based techniques are required to come up with a

Table 6 Factors and their levels

\begin{tabular}{lllll}
\hline Levels & $\begin{array}{l}\text { Current } \\
(\mathrm{A})(I)\end{array}$ & $\begin{array}{l}\text { Pulse on-time } \\
(\mu \mathrm{s})\left(T_{\mathrm{on}}\right)\end{array}$ & $\begin{array}{l}\text { Voltage } \\
(\mathrm{V})(V)\end{array}$ & $\begin{array}{l}\text { Duty cycle } \\
(\%)\end{array}$ \\
\hline-1 & 5 & 25 & 50 & 50 \\
0 & 10 & 50 & 65 & 65 \\
1 & 20 & 100 & 80 & 80 \\
\hline
\end{tabular}


Fig. 17 Main effect plots for MRR a
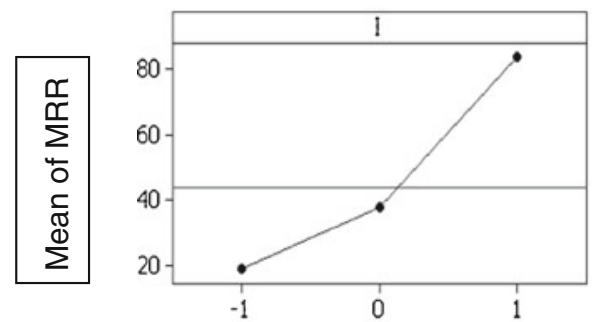

C

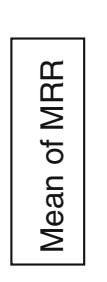

b

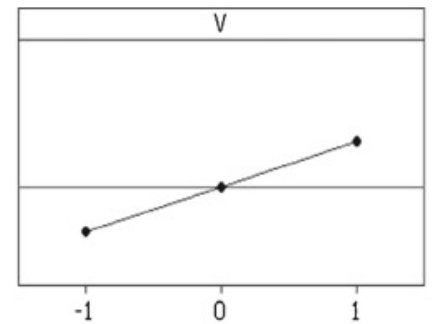

d

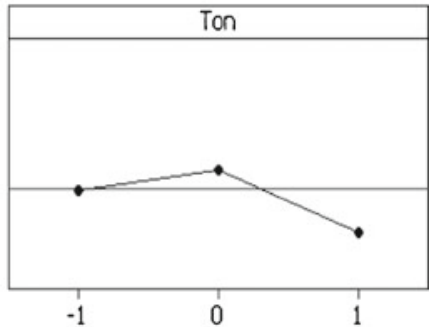

solution to PFE calculations. The application of these techniques demands for on-line acquisition, recording, and counting of various pulse forms, i.e., normal, arc, open, and short circuiting case. So, an oscilloscope of storage type and an in-house-developed electronic circuit have been implemented to capture the time history of gap voltage and current. NILABVIEW program was implemented for data acquisition and storage. The recorded data have been transferred into the developed MATLAB code to calculate the number of different kinds of pulses based on pulse ignition time, and then Eqs. 24 and 25 were used to compute PFE. In order to investigate the effect of process parameters on PFE, parametric studies were carried out and variations of PFE versus pulse current and pulse on-time were recorded, which are illustrated in Fig. 11.

$\mathrm{PFE}=\frac{V_{\text {exp }}}{V_{\mathrm{th}}} \times 100$

$V_{\exp }=M_{1}-M_{2} / \rho \times N_{\mathrm{np}}$

In these equations, $V_{\text {th }}$ is the crater volume calculated in the previous section, $M_{1}$ and $M_{2}$ denote the mass of workpiece specimen before and after machining $(\mathrm{kg}), \rho$ is the workpiece density in room temperature $\left(\frac{\mathrm{kg}}{\mathrm{m}^{3}}\right)$, and $N_{\mathrm{np}}$ is the number of normal discharges.

MRR is defined as the ratio of volume removed from the workpiece per pulse duration, so theoretical MRR $\left(\frac{\mathrm{mm}^{3}}{\mathrm{~min}}\right)$ reads as:

$\mathrm{MRR}_{T}=\frac{V_{\text {th }} \times \text { PFE }}{T_{\text {on }}+T_{\text {off }}}$

where $T_{\text {on }}$ is pulse on-time ( $\min$ ) and $T_{\text {off }}$ is the discharge off- time (min).

\section{Model validation}

In order to verify the theoretical MRR, the experimental results of Dibitonto et al. [8] have been used. As shown in Fig. 12, the proposed model predicts results closer to experimental data for a wide range of discharge powers up to $1,100 \mathrm{~W}$. It is clear from the figure that applying the effect of phase change and latent heat
Fig. 18 a Surface plot for MRR versus pulse current and voltage. b Surface plot for MRR versus pulse voltage and duty cycle
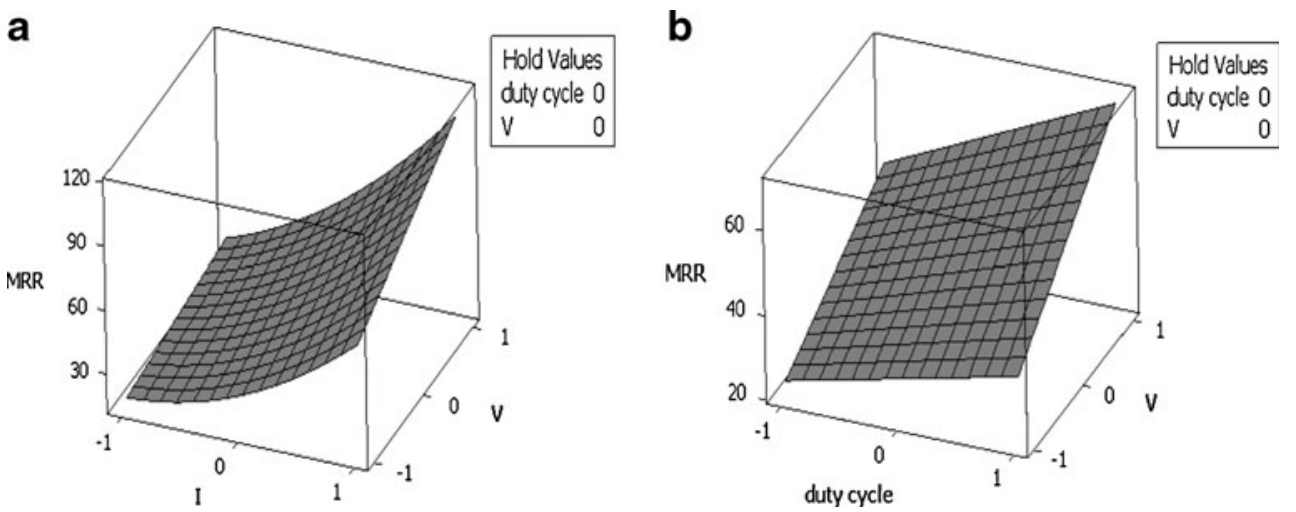
Table 7 ANOVA table for factors

Estimated regression coefficients for MRR

\begin{tabular}{lllll}
\hline Term & Coefficient & SE coefficient & $T$ & $P$ \\
Constant & 42.5350 & 1.2277 & 34.646 & 0.000 \\
$I$ & 32.5037 & 0.6139 & 52.950 & 0.000 \\
Ton & -6.0820 & 0.6139 & -9.908 & 0.000 \\
Duty cycle & 9.5128 & 0.6139 & 15.497 & 0.000 \\
$V$ & 13.6179 & 0.6139 & 22.184 & 0.000 \\
$I^{*} I$ & 11.5599 & 0.9208 & 12.554 & 0.000 \\
$T_{\text {on }}{ }^{*} T_{\text {on }}$ & -9.8656 & 0.9208 & -10.714 & 0.000 \\
Duty cycle*duty cycle & 0.5433 & 0.9208 & 0.590 & 0.566 \\
$V^{*} V$ & 0.5433 & 0.9208 & 0.618 & 0.548 \\
$I^{*} T_{\text {on }}$ & -2.1690 & 1.0632 & -2.040 & 0.064 \\
$I^{*}$ duty cycle & 8.0105 & 1.0632 & 7.534 & 0.000 \\
$I^{*} V$ & 8.1070 & 1.0632 & 7.625 & 0.000 \\
$T_{\text {on }} *$ duty cycle & -1.4338 & 1.0632 & -1.348 & 0.202 \\
$T_{\text {on }} * V$ & 0.5432 & 1.0632 & 0.511 & 0.619 \\
Duty cycle* $V$ & 3.3100 & 1.0632 & 3.113 & 0.009 \\
\hline
\end{tabular}

$S=2.12645$, PRESS $=312.547, R^{2}=99.71 \%, R^{2}$ (pred) $=98.35 \%, R^{2}$ $(\operatorname{adj})=99.38 \%$

of fusion has a considerable effect on the results and makes them closer to the experimental data. For higher values of discharge powers $(>1,100 \mathrm{~W})$, the proposed model underestimates the MRR. This is possibly because an equivalent spark radius equation given by Ikai and Hashiguchi [18] which has been used in the present work, is not valid for the very high discharge powers.

The comparison process described earlier ensures the accuracy of the analysis; MRR simulation on AISI H13 tool steel can be confidently used to precisely determine the energy distribution factor for this common material. Results for theoretical MRR in different machining conditions and different $F_{\mathrm{c}}$ values for H13 tool steel are shown in Table 3.

\subsection{Experimental studies for model validation}

Prior to EDM, the workpiece (AISI H13 tool steel) was cut in cylindrical shapes. Specimens were hardened, and their hardness increased up to $60 \mathrm{HRC}$. They were ground and prepared for the
EDM process. Figure 13 shows the work and tool specimens and their dimensions. Experiments were conducted on the die sinking EDM machine ELECTRONICA-ELECTRAPULSE PS 50ZNC, as shown in Fig. 14a. The discharge power levels were varied between 220 and 3,169 W during machining by setting appropriate process parameters (current, pulse on-time, discharge voltage, and pulse off-time) on the machine. EDM-processed workpieces are illustrated in Fig. 14b, and EDM parameters are listed in Table 4.

Precise determination of the removed material from the workpiece is essential to calculate the experimental MRR. Therefore, a digital balance with a resolution of $0.001 \mathrm{gr}$ was used for weighing workpieces before and after EDM, and the amount of removed material was recorded; then, Eq. 27 was used to calculate the experimental MRR:

$\mathrm{MRR}_{\exp }=\left(M_{1}-M_{2}\right) / \rho \times t$

In this equation, $M_{1}$ and $M_{2}$ are the mass of workpiece before and after EDM, respectively, and $t$ is the machining time (20 min in this study). Results for experimental MRR are shown in Table 5.

\subsection{Comparison between theoretical and experimental MRR}

Figure 15 shows the comparison of the MRR observed during the experiments and the values predicted with the proposed thermo-physical model. It is clear that a suitable convergence between the mentioned data is achieved when $F_{\mathrm{c}}$ is considered as $5 \%$. Since the capability of materials in absorbing energy is different, the value of 0.183 , which was reported by Dibitonto [8] and used in many other studies, cannot be used for AISI H13 tool steel. Determination of an exact value for $F_{c}$, applying PFE and latent heat of fusion, made the proposed model more realistic. As mentioned earlier the proposed model is not valid for higher range of discharge powers, so the convergence between experimental and theoretical data continues up to 2,000 W and beyond this value their tendency changes.

In order to check the accuracy of calculated values of $F_{\mathrm{c}}$, the calculated theoretical MRR is collated with the data reported in the literature. Since simulation of MRR on H13
Table 8 ANOVA table for updated regression analysis

$D F$ degree of freedom, $S S$ sum of square, $M S$ mean square, $F F$ value, $P P$-value

\begin{tabular}{lllllll}
\hline \multicolumn{2}{l}{ Analysis of variance for MRR } & \multicolumn{7}{l}{} \\
\hline Source & DF & SEq SS & Adj SS & Adj MS & $F$ & $P$ \\
\hline Regression & 9 & $18,836.1$ & $18,836.1$ & $2,092.9$ & 418.78 & 0.000 \\
Linear & 4 & $16,433.0$ & $16,433.0$ & $4,108.3$ & 822.04 & 0.000 \\
Square & 2 & $1,839.7$ & $1,839.7$ & 919.8 & 184.05 & 0.000 \\
Residual error & 17 & 85.0 & 85.0 & 5.0 & - & - \\
Lack of fit & 15 & 85.0 & 85.0 & 5.7 & - & - \\
Pure error & 2 & 0.0 & 0.0 & 0.0 & - & - \\
Total & 26 & $1,8921.0$ & - & - & - & - \\
\hline
\end{tabular}


tool steel has no longer been conducted and there is no data for theoretical MRR in the literature for H13 tool steel, we have verified the veracity of our results with Joshi's [16] outputs, who carried out a MRR study on AISI P20 mold steel that has similar thermal and mechanical properties to AISI H13.

Comparison between calculated MRR and those obtained by Joshi [16] has been shown in Fig. 16. As is clear from the figure, the proposed model predicts MRR closer to the experimental data either with or without considering PFE when compared with the one reported by Joshi et al. [16] for a wide range of discharge power levels.

\section{Parametric studies on MRR}

After verification of the proposed model, it was decided to investigate the effect of EDM parameters on the MRR. The DOE technique has been used as a powerful tool which allows to model and analyze the influence of determined process variables over other specified variables, which are usually known as response variables [21].

Table 6 shows the selected variables and their levels. These levels were selected in a way to restrict discharge power not to exceed 2,000 W as the model loses its accuracy beyond this value. RSM was employed and the main effects for MRR were plotted. Estimated response surface of MRR was also presented to illustrate how MRR changes with process parameters.

\subsection{Main effects and estimated response surfaces for MRR}

Figure $17 \mathrm{a}-\mathrm{d}$ shows the main effect plots for the MRR. It should be mentioned that these plots illustrate the mean values versus factor levels. Based on these plots, the effect of each factor can be determined. As can be seen in Fig. 17a, $b$, MRR increases when pulse current and voltage increase.
This tendency was expected in advance as the use of more energetic pulses produces surface craters of greater size, and therefore MRR will increase.

Duty cycle is another important factor that can affect MRR. It is defined as the ratio of pulse on-time to total spark time and indicates the number of sparks that take place in the process. Figure $17 \mathrm{c}$ illustrates that when the duty cycle values go up, MRR monotonically soars as the number of sparks increase. The last factor that is considered in this study for investigation of MRR is the pulse on-time. As illustrated in Fig. 17d, MRR initially increases with pulse on-time, reaches a maximum value, and then starts to diminish. That is because the plasma channel gradually expands from time to time and energy density decreases. These trends for MRR are the same with the results of Puertas et al. [24], who reported the experimental method.

In Fig. 18a, the estimated response surface of MRR versus discharge current and discharge voltage is shown. As mentioned earlier, MRR increases when both factors increase within the work interval considered for this study. Finally, in Fig. 18b, the estimated response surface of MRR in function of discharge voltage and duty cycle is depicted. The interaction between these factors can be clearly appreciated.

\subsection{Regression model}

A quadratic polynomial regression model in terms of factors was proposed for MRR, which is shown in Eq. 28:

$$
\begin{aligned}
& \text { MRR }=45.535+32.503 I-6.082 T_{\text {on }}+9.512 \text { duty cycle }+13.617 V \\
& +11.559 I * I-2.1690 I * T_{\text {on }}+8.010 I * \text { duty cycle } \\
& +8.107 I * V-9.865 T_{\text {on }} * T_{\text {on }}-1.433 T_{\text {on }} * \text { duty cycle } \\
& +0.5432 T_{\text {on }} * V+0.543 \text { duty cycle } * \text { duty cycle } \\
& +3.310 \text { duty cycle } * V+0.5433 V * V
\end{aligned}
$$

Values of 0.9971 and 0.9938 were obtained for $R^{2}$ and $R_{\text {adj }}^{2}$ statistics, respectively. $R^{2}$ and $R_{\text {adj }}^{2}$ are powerful tools to
Fig. 19 a Plot of residuals versus fits. b Plot of residuals versus order of the data. $\mathbf{c}$ Normal plot of residuals. d Histogram for residuals a
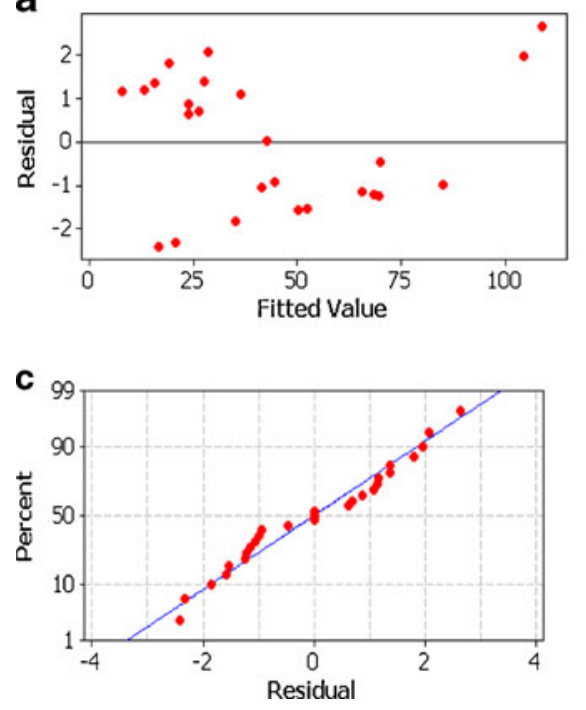

b

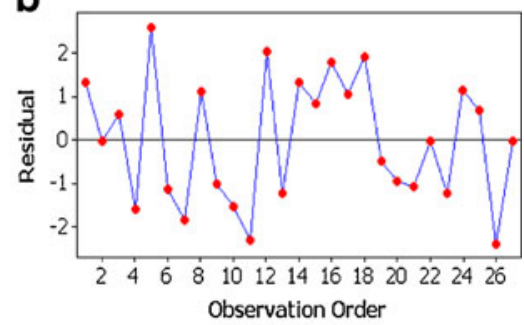

d

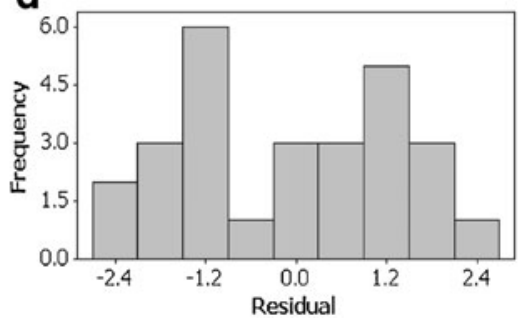


evaluate the accuracy of regression models. Both values indicate that the presented model fits the data very well. Analysis of variance (ANOVA) was conducted for regression model to identify significant factors. ANOVA table is shown in Table 7. For the confidence level of $95 \%$, factors with a $P$-value of more than $5 \%$ would not have a significant effect in the model. Thus, insignificant factors were removed from it to simplify the model, and finally the updated regression model was obtained, which is shown in Eq. 29.

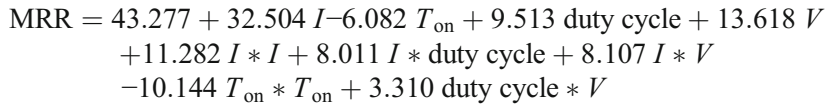

$R^{2}$ and $R_{\text {adj }}^{2}$ were obtained as 0.9955 and 0.9931 for the updated model, respectively.

The analysis of variance for the updated regression model is shown in Table 8. The $p$-value for the regression model shows that the model is significant at $a$-level of 0.05 .

Model adequacy was also checked by means of plot of residuals versus fits, plot of residuals versus order of the data, normal plot of residuals, and histogram for residuals. Figure 19a shows the plot of residuals versus fits. It is clearly observed from this plot that residuals have a constant variance. Plot of residuals versus order of the data is illustrated in Fig. 19b. This figure indicates that residuals are independent of one another. Also, normal plot of residuals and histogram for residuals are shown in Fig. 19c, d, respectively. It can be easily found out from these figures that residuals are normally distributed [23].

\section{Conclusions}

Thermal modeling of electrical discharge machining of AISI H13 tool steel was carried out in this research, and the presented model was solved numerically by means of ANSYS finite element code. Incorporating factors such as plasma flushing efficiency, latent heat of melting, and Gaussian distribution of heat flux, considering material properties as a function of temperature, and calculating an exact value for the portion of energy absorbed by the cathode made the proposed model more realistic compared to the models available in the literature. Theoretical MRR was calculated in various pulse powers and compared with experimental results. The comparison process allowed us to calculate the exact value of energy distribution factor for the cathode. In order to investigate the variation of MRR versus EDM parameters, the techniques of design of experiments and response surface methodology were employed and the effect of each factor was determined. A quadratic polynomial regression model has been proposed for the MRR, and the accuracy of the model was checked by analysis of variance and residuals study.
The main results of this work can be summarized as follows:

- Energy distribution factor for the cathode (AISI H13) is calculated as $5 \%$.

- The presented model loses its accuracy for discharge powers of more than $2,000 \mathrm{~W}$, so this model is well suited for finishing EDM operations.

- Parametric studies on MRR showed that an increase in current, voltage, and duty cycle values boosts MRR, but by increasing pulse on-time, MRR initially increases until a maximum value and then starts to diminish.

- Analysis of variance conducted on factors revealed that second-order effects of duty cycle and voltage and interactions of current and pulse on-time, pulse on-time, and duty cycle and pulse on-time and discharge voltage do not have a significant effect in the model and can be neglected.

- Inspection of $R^{2}$ and $R_{\mathrm{adj}}{ }^{2}$ statistics and residuals showed that a second-order regression model is an appropriate model for the MRR.

\section{References}

1. Haron CH, Deros B, Ginting A, Fauziah M (2001) Investigation on influence of machining parameters when machining tool steel using EDM. J Mater Process Technol 116:84-87

2. Snoeys R, Van Dijck FS (1971) Investigation of electro discharge machining operations by means of thermo-mathematical model. CIRP Ann 20:35-37

3. Van Dijck FS, Dutre WL (1974) Heat conduction model for the calculation of the volume of molten metal in electric discharges [discharge machining]. J Phys D (Appl Phys) 7:899-910

4. Beck JV (1981) Transient temperatures in a semi-infinite cylinder heated by a disk heat source. Int J Heat Mass Transfer 24:16311640

5. Beck JV (1981) Large time solutions for temperatures in a semiinfinite body with a disk heat source. Int $\mathrm{J}$ Heat Mass Transfer 24:155-164

6. Jilani ST, Pandey PC (1982) Analysis and modeling of EDM parameters. Precis Eng 4:215-221

7. Jilani ST, Pandey PC (1983) Analysis of surface erosion in electrical discharge machining. J Wear 84:275-84

8. Dibitonto D, Eubank P, Patel M, Barrufet M (1989) Theoretical models of the electrical discharge machining process. J Appl Phys 66:4095-4103

9. Panda DK, Bhoi RK (2001) Developing transient threedimensional thermal models for electro discharge machining of semi-infinite and infinite solid. J Mater Process Manuf Sci 10:7190

10. Yadav V, Jain V, Dixit P (2002) Thermal stresses due to electrical discharge machining. Int J Mach Tool Manuf 42:877-888

11. Shankar P, Jain VK, Sundarajan T (1997) Analysis of spark profiles during EDM process. Mach Sci Technol 1:195-217

12. Das S, Klotz M, Klocke F (2003) EDM simulation: finite-element based calculation of deformation, microstructure and residual stresses. J Mater Process Technol 142:434-351 
13. Allen P, Chen X (2007) Process simulation of micro electro-discharge machining on molybdenum. J Mater Process Technol 186:346-355

14. Kansal H, Singh S, Kumar P (2008) Numerical simulation of powder mixed electric discharge machining (PMEDM) using finite element method. Math Comput Model 47:1217-1237

15. Yeo SH, Kurnia W, Tan PC (2008) Critical assessment and numerical comparison of thermal models in EDM. J Mat Process Technol 203:241-251

16. Joshi S, Pande SS (2010) Thermo-physical modeling of diesinking EDM process. J Manuf Process 12:45-56

17. Shabgard M, Seyedzavar M, Nadimi S (2011) A numerical method for predicting depth of heat affected zone in EDM process for AISI H13 tool steel. J Sci Ind Res 70:493-499

18. Ikai T, Hashigushi K (1995) Heat input for crater formation in EDM. Proceeding of International Symposium for Electromachining-ISEM 163-170.

19. Eubank P, Patel M, Barrufet M, Bozkurt B (1993) Theoretical models of the electrical discharge machining process. Part III: the variable mass, cylindrical plasma model. J Appl Phys 73:7900-7909

20. Erden A (1983) Effect of materials on the mechanism of electric discharge machining (EDM). Transactions of ASME. J Eng Mater Technol 108:247-251
21. Puertas I, Luis CJ, Villa G (2005) Spacing roughness parameters study on the EDM of silicon carbide. J Mater Process Technol 164-165:1590-1596

22. Montgomery DC (2009) Introduction to statistical quality control, 6th edn. Wiley, Hoboken

23. Zarepour H, FadaeiTehrani A, Karimi D, Amini S (2007) Statistical analysis on electrode wear in EDM of tool steel DIN 1.2714 used in forging dies. J Mater Process Technol 187-188:711-714

24. Puertas I, Luis CJ, Alvarez L (2004) Analysis of the influence of EDM parameters on surface quality, MRR, and EW of WC-Co. J Mater Process Technol 153-154:1026-1032

25. Shabgard M, Ahmadi R, Seyedzavvar S, Nadimi S (2013) Mathematical and numerical modeling of the effect of input-parameters on the flushing efficiency of plasma channel in EDM process. Int $\mathrm{J}$ Mach Tool Manuf 65:79-87

26. Ekmekci B, Tekkaya A, Erden A (2006) A semi empirical approach for residual stresses in electrical discharge machining. Int J Mach Tool Manuf 46:858-868

27. Kumar PD (2008) Study of thermal stresses induced surface damage under growing plasma channel in electro-discharge machining. J Mater Process Technol 202:86-95 